\title{
Eddington ratios of faint AGN at intermediate redshift: evidence for a population of half-starved black holes ${ }^{\star}$
}

I. Gavignaud ${ }^{1}$, L. Wisotzki ${ }^{1}$, A. Bongiorno ${ }^{2}$, S. Paltani ${ }^{3,4}$, G. Zamorani ${ }^{5}$, P. Møller ${ }^{6}$, V. Le Brun ${ }^{7}$, B. Husemann ${ }^{1}$, F. Lamareille ${ }^{8}$, M. Schramm ${ }^{1}$, O. Le Fèvre ${ }^{7}$, D. Bottini ${ }^{9}$, B. Garilli ${ }^{9}$, D. Maccagni ${ }^{9}$, R. Scaramella ${ }^{10,11}$, M. Scodeggio ${ }^{9}$,

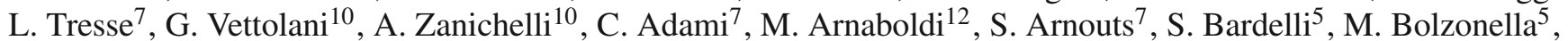
A. Cappi ${ }^{5}$, S. Charlot ${ }^{13}$, P. Ciliegi ${ }^{5}$, T. Contini ${ }^{8}$, S. Foucaud ${ }^{14}$, P. Franzetti ${ }^{9}$, L. Guzzo ${ }^{15}$, O. Ilbert $^{16}$, A. Iovino ${ }^{15}$, H. J. McCracken ${ }^{13,17}$, B. Marano ${ }^{18}$, C. Marinoni ${ }^{8}$, A. Mazure ${ }^{8}$, B. Meneux ${ }^{9,15}$, R. Merighi ${ }^{5}$, R. Pellò ${ }^{8}$, A. Pollo ${ }^{8}$, L. Pozzetti ${ }^{5}$, M. Radovich ${ }^{12}$, E. Zucca ${ }^{5}$, M. Bondi ${ }^{10}$, G. Busarello ${ }^{12}$, O. Cucciati ${ }^{15,18}$, S. de la Torre ${ }^{8}$, L. Gregorini ${ }^{10}$, Y. Mellier ${ }^{13,17}$, P. Merluzzi ${ }^{12}$, V. Ripepi ${ }^{12}$, D. Rizzo ${ }^{2}$, and D. Vergani ${ }^{9}$

1 Astrophysikalisches Institut Potsdam, An der Sternwarte 16, 14482 Potsdam, Germany e-mail: igavignaud@aip.de

2 Max-Planck-Institut für Extraterrestrische Physik, Giessenbachstr., 85741 Garching, Germany

3 Integral Science Data Centre, Ch. d'Écogia 16, 1290 Versoix, Switzerland

${ }^{4}$ Geneva Observatory, Ch. des Maillettes 51, 1290 Sauverny, France

5 INAF-Osservatorio Astronomico di Bologna, via Ranzani, 1, 40127, Bologna, Italy

${ }^{6}$ European Southern Observatory, Karl-Schwarzschild-Strasse 2, 85748 Garching bei München, Germany

7 Laboratoire d'Astrophysique de Marseille (UMR6110), CNRS-Université de Provence, 38 rue Frederic Joliot-Curie, 13388 Marseille Cedex 13, France

${ }^{8}$ Laboratoire d'Astrophysique de Toulouse-Tarbes, Université de Toulouse, CNRS, 14 avenue Édouard Belin, 31400 Toulouse, France

9 IASF-INAF, via Bassini 15, 20133, Milano, Italy

10 IRA-INAF, via Gobetti,101, 40129, Bologna, Italy

11 INAF-Osservatorio Astronomico di Roma, via di Frascati 33, 00040 Monte Porzio Catone, Italy

12 INAF-Osservatorio Astronomico di Capodimonte, via Moiariello 16, 80131 Napoli, Italy

13 Institut d'Astrophysique de Paris, UMR 7095, 98bis Bvd. Arago, 75014 Paris, France

14 School of Physics \& Astronomy, University of Nottingham, University Park, Nottingham, NG72RD, UK INAF-Osservatorio Astronomico di Brera, via Brera 28, Milan, Italy

15 Canada France Hawaii Telescope corporation, Mamalahoa Hwy, Kamuela, 96743, USA

16 Observatoire de Paris, LERMA, 61 avenue de l'Observatoire, 75014 Paris, France

17 Università di Bologna, Dipartimento di Astronomia, via Ranzani, 1, 40127, Bologna, Italy

18 Università di Milano-Bicocca, Dipartimento di Fisica, Piazza delle Scienze, 3, 20126 Milano, Italy

Received 29 October 2007 / Accepted 17 October 2008

\section{ABSTRACT}

We use one of the deepest spectroscopic samples of broad-line active galactic nuclei (AGN) currently available, extracted from the VIMOS VLT Deep Survey (VVDS), to compute the Mg II and C IV virial-mass estimates of 120 super-massive black holes in the redshift range $1.0<z<1.9$ and $2.6<z<4.3$. We find that the mass-luminosity relation shows considerably enhanced dispersion towards low AGN luminosities ( $\log L_{\text {bol }} \sim 45$ ). At these luminosities, there is a substantial fraction of black holes accreting far below their Eddington limit $\left(L_{\mathrm{bol}} / L_{\mathrm{Edd}}<0.1\right)$, in marked contrast to what is generally found for AGN of higher luminosities. We speculate that these may be AGN on the decaying branch of their lightcurves, well past their peak activity. This would agree with recent theoretical predictions of AGN evolution. In the electronic Appendix of this paper we publish an update of the VVDS type-1 AGN sample, including the first and most of the second-epoch observations. This sample contains 298 objects of which 168 are new.

Key words. galaxies: active - galaxies: Seyfert - galaxies: nuclei

\section{Introduction}

The mass scaling relations of super-massive black holes in present-day galaxies (e.g., Gebhardt et al. 2000; Ferrarese \& Merritt 2000) imply that black hole growth must be closely

\footnotetext{
* Based on data obtained with the European Southern Observatory Very Large Telescope, Paranal, Chile, program 070.A-9007(A), 272.A-5047, 076.A-0808, and partially on data obtained at the CanadaFrance-Hawaii Telescope.
}

connected to the overall formation and evolution of galaxies. Most of the mass locked up in black holes today was probably accumulated through accretion in discrete phases of nuclear activity, as suggested by the consistency between the estimate of the black hole mass density at $z \approx 0$ and that derived from the integrated AGN luminosity density (Soltan 1982; Yu \& Tremaine 2002; Marconi et al. 2004). 
Accretion histories of individual black holes are essentially unconstrained by observations. By looking at AGN one may at least catch snapshots of the black hole growth process, especially when black hole masses and thus accretion rates can be estimated. There has been significant progress in this direction over the past years, and it has been demonstrated that singleepoch spectroscopic and photometric measurements of AGN with broad emission lines (type $1 \mathrm{AGN}$ ) allow one to estimate black hole masses to an accuracy on the order of \pm 0.5 dex (Vestergaard 2002; McLure \& Jarvis 2002; Collin et al. 2006). With this approach it has been possible to explore the distribution of Eddington ratios for large AGN surveys (McLure \& Dunlop 2004; Kollmeier et al. 2006).

These studies have shown that powerful type 1 AGN appear to accrete at rates close to the Eddington limit with remarkable uniformity, and yet periods of activity must be followed by a transition from high-luminosity, near-Eddington states to almost quiescent black holes. Unless this transition is rather abrupt, there should also be a population of AGN with significantly lower Eddington ratios, but still recognizable as bona fide AGN. We report on observations of such a population at intermediate redshifts, based on black hole mass estimates that we derive for a new sample of faint AGN with complete spectroscopic identification.

In this work, absolute luminosities are computed assuming a flat universe with cosmological parameters $\Omega_{\mathrm{m}}=0.3, \Omega_{\Lambda}=0.7$, and $H_{0}=70 \mathrm{~km} \mathrm{~s}^{-1}$.

\section{The sample}

The VVDS (VLT-VIMOS Deep Survey) is a purely $I$-band flux limited spectroscopic survey designed to study the evolution of galaxies, AGN, and large-scale structure. It comprises two subsets: a "deep" survey with a limit of $I_{\mathrm{AB}} \leq 24$ (Le Fèvre et al. 2005) and a "wide" and a shallower survey with $I_{\mathrm{AB}} \leq 22.5$ (Garilli et al. 2008). Both surveys utilize the VIMOS multiobject spectrograph on the ESO-VLT to take spectra of objects above the flux limit, irrespective of their morphological properties or colors, albeit with a sparse target sampling rate (for details see the above-mentioned papers).

About $1 \%$ of all VVDS targets can be classified as type 1 AGN on the basis of their broad emission lines. From the VVDS we can therefore construct AGN samples that have two advantages over most other surveys. (i) The very faint limiting magnitude, which is even deeper than that of the multi-color photometric COMBO-17 survey (Wolf et al. 2003); and (ii) the simple selection criterion, which only requires the presence of a broad emission line $\left(F W H M \geq 1000 \mathrm{~km} \mathrm{~s}^{-1}\right)$ in any given spectrum. This way, we recently constructed a well-defined sample of type 1 AGN, which is described in detail by Gavignaud et al. (2006). In that paper we demonstrated that, since the sample is unaffected by morphological or color pre-selection biases, it is also much less prone to incompleteness due to host galaxy contamination. The sample has already been used to investigate the AGN luminosity function and its evolution (Bongiorno et al. 2007). Here we exploit the spectroscopic properties of that sample, containing 130 broad-line AGN, supplemented by 168 AGN of the VVDS second epoch data. The merged updated catalog of AGN is published in Appendix B of this paper. It contains 222 and 76 AGN from the "wide" and the "deep" survey respectively. The median redshift is $z \sim 1.8$ (roughly equal for the wide and deep subsets), with a broad distribution of redshifts within $1 \lesssim z \lesssim 3$.

\section{Black hole masses and Eddington ratios}

In order to estimate the black hole masses in type 1 AGN from single epoch spectroscopy, it must be assumed that the lineemitting "clouds" are roughly in virial equilibrium, and that the size of the broad-line region (BLR) is closely correlated with the luminosity of the AGN. The black hole mass is then given by the virial relation (Collin et al. 2006), $M_{\mathrm{BH}}=f\left(R \Delta V^{2}\right) / \mathcal{G}$, where $\mathcal{G}$ is the gravitational constant, $R$ is the size of the BLR, which in turn is estimated from the continuum luminosity, $f$ is a dimensionless factor close to unity which reflects the unknown geometry and inclination of the BLR, and $\Delta V$ represents the velocity broadening of a given broad emission line. $\Delta V$ can be estimated using either the line $F W H M$ or the line velocity dispersion $\sigma_{1}$.

We have applied this approach to our sample of 298 type 1 AGN. The spectral range available for measuring line widths is $5700 \AA-8200 \AA$. Consequently, for $1.0 \lesssim z \lesssim 1.9$, the spectra contain the Mg II $\lambda 2798$ emission line, while C IV $\lambda 1550$ is accessible for $2.6 \lesssim z \lesssim 4.3$.

In the case of $\mathrm{Mg}$ II, we applied an iterative procedure to subtract the Fe II contamination from the AGN continuum using a template kindly provided by Vestergaard (see Vestergaard \& Wilkes 2001). Since this template is derived from the observed spectrum of a narrow line Seyfert I, it is difficult to deblend the Fe II pseudo-continuum emission from other emission lines. In particular, the template contains no flux under the $\mathrm{Mg}$ II line itself although some amount of flux is expected from theoretical models (Sigut \& Pradhan 2003). The effect of adding flux to the empirical template has been recently quantified by Fine et al. (2008) and is found to be negligible in view of the other errors. In this work we used the unmodified template.

The Mg II and C IV emission line profiles were modeled by a superposition of two Gaussian components; the line widths were obtained from these fits. The measurements were then corrected for the finite spectrograph resolution assuming that $\Delta \lambda_{\mathrm{obs}}^{2}=\Delta \lambda_{\text {intrinsic }}^{2}+\Delta \lambda_{\mathrm{res}}^{2}$. The mean instrumental resolution of the VVDS spectra corresponds to $\Delta \sigma_{\text {res }}=350 \mathrm{~km} \mathrm{~s}^{-1}$. Errors on the velocity measurements are obtained by combining the nominal errors of the fit parameters and the uncertainties due to the adopted continuum level. Figure 1 shows two examples of fits to the spectra (continuum + emission lines) representative for the two redshift intervals.

Objects with a mean signal-to-noise $(S / N)$ ratio per pixel lower than 7 , in the vicinity of the emission line, were excluded from further analysis (this concerns $8 \mathrm{Mg}$ II and $8 \mathrm{C}$ IV objects). 20 of the high-redshift $C$ IV line profiles and 4 of the low-redshift Mg II were heavily affected by associated absorption or instrumental problems, and these were also eliminated. After these cuts we remained with a sample of 120 objects, 91 of which feature the Mg II, and 29 of which feature the C IV line. The median redshift is 1.5 for the $\mathrm{Mg}$ II subsample and 3.1 for the C IV subsample, respectively.

We flux-calibrated our spectra by scaling them to the $I$ band photometry in the CFHT images used as input to the VVDS. Monochromatic luminosities at given rest-frame wavelengths were then directly measured from the spectra.

In order to apply the virial relation to measurements of the $\mathrm{Mg}$ II emission line we used the empirical calibration by McLure \& Dunlop (2004)

$\log \frac{M_{\mathrm{BH}}}{M_{\odot}}=\log \left(F W H M_{1000}^{2}\left((\lambda L)_{443000}\right)^{0.62}\right)+6.51$ 

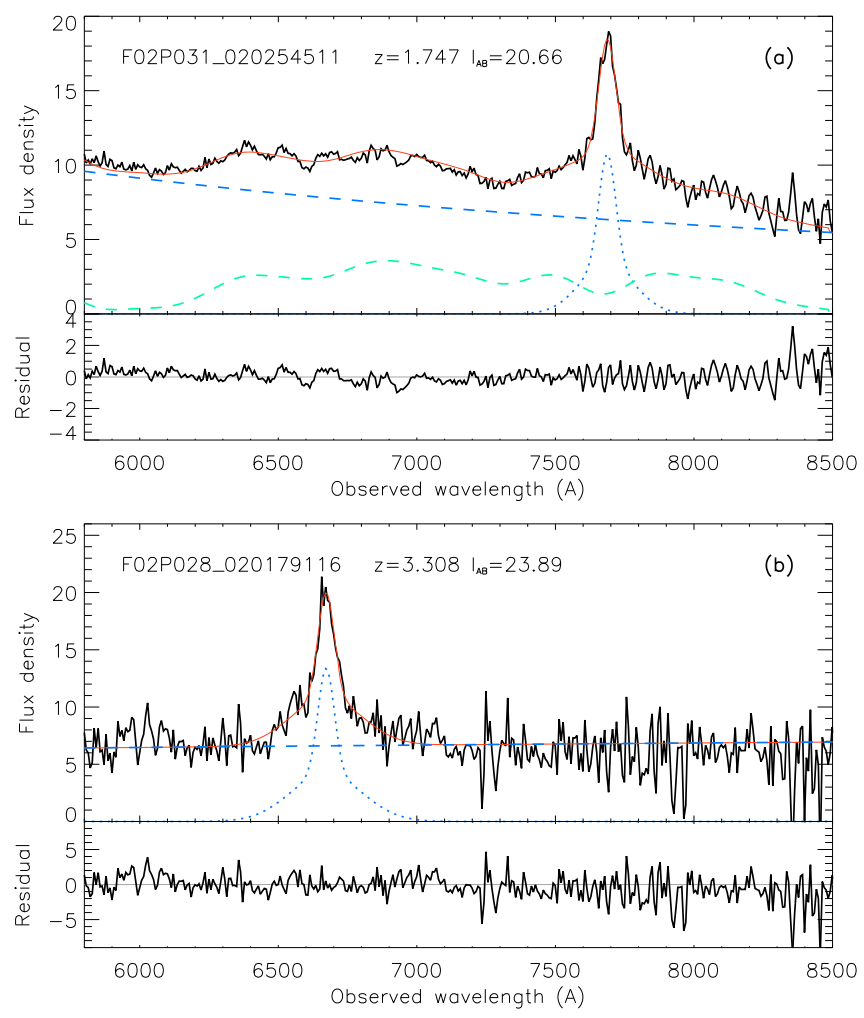

Fig. 1. Two examples of emission line fits to the spectra. In a) we show an object from our low-redshift sample with the $\mathrm{Mg}$ II line and in b) an example of the high-redshift sample with the CIV line. The observed spectra are displayed in black, the fits are overplotted in red. Each fit is a combination of a power-law continuum (blue dashed line), a double-Gaussian model of the broad emission line (blue dotted line) and, only for the Mg II sample, a broadened empirical template of the Fe II pseudo-continuum emission (green dashed-line).

where $F W H M_{1000}$ is the $F W H M$ of the line in units of $1000 \mathrm{~km} \mathrm{~s}^{-1}$, and $\lambda L_{443000}$ is the monochromatic luminosity at $\lambda=3000 \AA$, expressed in units of $10^{44} \mathrm{erg} \mathrm{s}^{-1}$.

For AGN where only C IV could be measured, we employed the recent relation by Vestergaard \& Peterson (2006),

$\log \frac{M_{\mathrm{BH}}}{M_{\odot}}=\log \left(\sigma_{1000}^{2}\left((\lambda L)_{44,1350}\right)^{0.53}\right)+6.73$

where $\sigma_{1000}$ is the emission line velocity dispersion in units of $1000 \mathrm{~km} \mathrm{~s}^{-1}$ and $(\lambda L)_{441350}$ is the monochromatic luminosity at $1350 \AA$, expressed in units of $10^{44} \mathrm{erg} \mathrm{s}^{-1}$.

Bolometric luminosities were derived from the monochromatic ones, multiplied by a correction factor $f_{\text {bol }}$. It is now established that, on average, at UV and optical wavelengths this correction factor increases towards lower luminosities (e.g. Richards et al. 2006; Steffen et al. 2006). Hopkins et al. (2007) provide an empirical model of AGN SED which varies with bolometric luminosity and is calibrated from a large number of observational studies ${ }^{1}$. Following this model, $f_{\text {bol }}(3000 \AA)$ decreases from 6.8 to 5.6 over the luminosity range $\log L_{\text {bol }}=$ [44.8, 46.2], while $f_{\text {bol }}(1350 \AA)$ varies between 4.2 and 3.7 for $\log L_{\mathrm{bol}}=[45.2,46.4]$.

Together with black hole masses and bolometric luminosities we also estimated the dimensionless "Eddington ratios"

1 See

http://www.cfa.harvard.edu/ phopkins/Site/qlf.html and references therein.
$\epsilon=L_{\mathrm{bol}} / L_{\mathrm{Edd}}$, where $L_{\mathrm{Edd}}$ is the Eddington luminosity of the black hole assuming spherically symmetric accretion.

\section{Results}

The distribution of the inferred $\mathrm{BH}$ masses versus bolometric luminosities is shown Fig. 2a. As expected, there is a trend of $M_{\mathrm{BH}}$ increasing with $L_{\mathrm{bol}}$. The overall mean and associated error of the BH masses for the full sample is $\log M_{\mathrm{BH}}=8.28 \pm 0.04$. We split our sample at $\log L=45.7$ into a "low luminosity" and a "high luminosity" subset, containing respectively 62 and 58 objects. The corresponding mean $\mathrm{BH}$ masses are $8.00 \pm 0.05$ and $8.57 \pm 0.04$, respectively. However, the trend is not consistent with the assumption of $L_{\mathrm{bol}} \propto M_{\mathrm{BH}}$, i.e. with an Eddington ratio $\epsilon$ independent of AGN luminosity. This is highlighted in Fig. 2b, where we plot $\epsilon$ versus $L_{\text {bol }}$ for the same objects. The mean $\log \epsilon$ for the full sample is $-0.71 \pm 0.03$ and has a dispersion of 0.33 dex. For the "low luminosity" sample the mean is $\log \epsilon=-0.81 \pm 0.04$, and for the "high luminosity" subset $\log \epsilon=-0.61 \pm 0.03$.

The dispersion of $\epsilon$ differs even more strongly between low and high luminosity subsets: for $\log L_{\text {bol }}>45.7$, there is little spread in $\epsilon$ (1st and 3rd quartiles in $\log \epsilon$ are -0.79 and -0.44). For $\log L_{\text {bol }}<45.7$, however, the spread is larger, with 1st and 3 rd quartiles being -1.06 and -0.55 , respectively. A similar behavior is observed for other percentiles. A Kolmogorov-Smirnov test comparing the distribution of $\epsilon$ in the two subsets gives a probability of only $1.8 \%$ that both subsets were drawn from the same parent population; thus, the two subsets have significantly different distributions in their Eddington ratios.

Most of the difference between the two $\epsilon$ distributions is due to the existence of a significant tail of low $\epsilon$ values for the low luminosity AGN. In fact, the fraction of slowly accreting black holes with $\epsilon<0.1$ for the AGN with $\log L_{\text {bol }}<45.7(16 / 62)$ is five times larger than the same fraction for those with $\log L_{\mathrm{bol}}>$ 45.7 (3/58). The significance of the difference in this tail, derived on the basis of a Fisher exact test on a $2 \times 2$ contingency table, is at about the $3 \sigma$ level.

The large number of low- $\epsilon$ AGN at low luminosities produces an apparent trend of $\epsilon$ increasing with $L_{\mathrm{bol}}$. A formal regression gives $\log \epsilon=-0.89+0.30\left(\log L_{\text {bol }}-45\right)$. We caution however against an overinterpretation of that trend, as our sample covers only a limited range of luminosities. A much wider luminosity range would be needed to establish a robust $\epsilon\left(L_{\mathrm{bol}}\right)$ relation (but see the discussion in Sect. 5.1 and Fig. 4). Moreover, as also discussed below, the slope of this relations depends on the choice of the exponent of the empirical luminosity-size relation adopted in the virial scaling relations. The linear-Pearson $(r)$ and Spearman-rank $(\rho)$ correlation coefficients between $\log L_{\mathrm{bol}}$ and $\log \epsilon$ taken alone indicate a mild correlation $(r=0.40$ and $\rho=0.37$, respectively).

About $75 \%$ of the AGN in our sample belong to the lowredshift, $\mathrm{Mg}$ II subsample at an average redshift of $\sim 1.5$. Since higher redshift AGN in the sample have, on average, higher luminosities, the CIV sample is populating mostly the "high luminosity" region of Fig. 2. In the overlapping luminosity range (45.5 $\lesssim \log L_{\text {bol }} \lesssim 46.4$ ), the AGN in the two redshift intervals have similar mean Eddington ratios or $\mathrm{BH}$ masses. However the high redshift objects seem to follow a steeper and tighter $\log \epsilon=\alpha \log L_{\text {bol }}+$ const. relation $(\alpha=0.40, r=0.75)$ than the low redshift sample ( $\alpha=0.22, r=0.24$ ). Interestingly, the difference in the best fit slope $\alpha$ between the two subsamples disappears if one adopts scaling relations with the same 

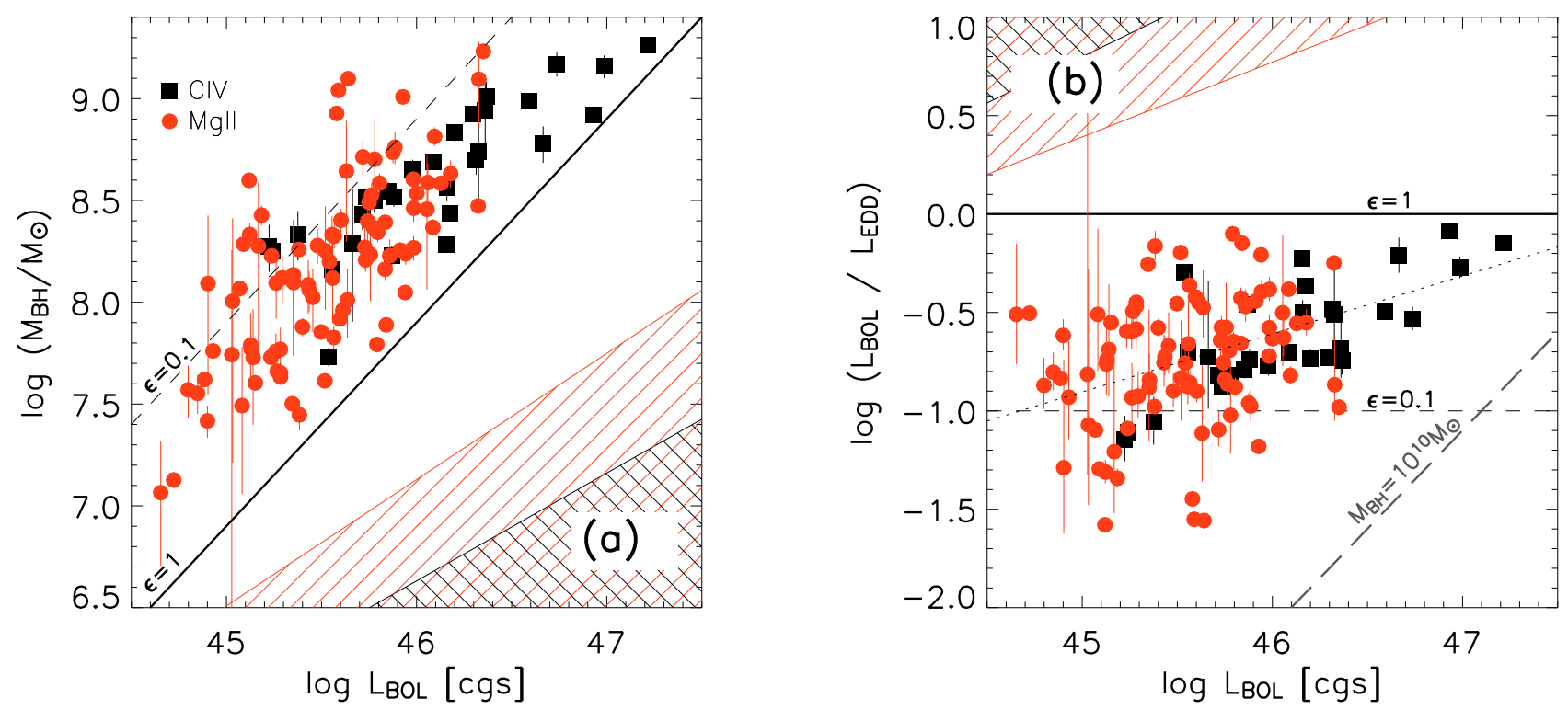

Fig. 2. Distribution of inferred BH masses (left) and Eddington ratios (right) versus AGN bolometric luminosities for the VVDS sample. The solid line and the dashed line correspond to Eddington ratios of $\epsilon=1$ and $\epsilon=0.1$, respectively. Different symbols denote the emission line used for the mass estimate: red filled circles indicate that the black hole masses were derived from $\mathrm{Mg}$ II, while the black squares correspond to C IV. Error bars correspond to our uncertainties on the line width measurements. Inside the hashed regions, AGN would have emission lines with $F W H M<1000 \mathrm{~km} \mathrm{~s}^{-1}$ implying that they would have been missed in our sample. The dotted line in panel b) shows a linear regression relation. (This figure is available in color in electronic form.)

size-luminosity exponent $\gamma$. However, also in this case, the correlation would have a smaller scatter for the C IV AGN than for the $\mathrm{Mg}$ II AGN.

We now consider possible sources of systematic errors, starting with sample incompleteness. Obviously, a selection bias against low mass black holes with high Eddington ratios would depopulate the lower left part of the left panel in Fig. 2, where AGN with high $\epsilon$ would be located. AGN with low $M_{\mathrm{BH}}$ and high $\epsilon$ are characterized by relatively narrow emission lines. As the VVDS AGN sample is defined through the detection of broad emission lines in low-resolution spectra, such a selection bias can in principle exist. However, from the spectral resolution of $350 \mathrm{~km} \mathrm{~s}^{-1}$ we expect the sample to be reasonably complete for lines intrinsically broader than $\sim 1000 \mathrm{~km} \mathrm{~s}^{-1}$. This is shown in Fig. 2 where the areas of incompleteness corresponding to $F W H M \leq 1000 \mathrm{~km} \mathrm{~s}^{-1}$ are marked as hashed regions. It is clear that the lack of high $\epsilon$ objects among the low luminosity AGN cannot predominantly be due to limited spectral resolution.

Since we are probing the AGN population down to low luminosities, host galaxy contamination could cause us to overestimate AGN continuum luminosities. This would lead to an overestimation of $\mathrm{BH}$ masses $\left(M_{\mathrm{BH}} \propto L^{\gamma}\right)$ as well as Eddington ratios $\left(\epsilon \propto L^{1-\gamma}\right)$. We use here the result of the SED analysis presented in Bongiorno et al. (2007) to estimate the host galaxy contribution to the total continuum flux. The multi-wavelength coverage necessary for this analysis is available for about a fourth of the objects of our sample. Most of them (23/28) are in the low redshift range. Figure 3 is a version of Fig. $2 b$, corrected for this effect. We find that host contamination at $1500 \AA$ is negligible for all our objects. At $3000 \AA$, this correction exceeds 0.1 dex in term of bolometric luminosities for 6 out of 23 AGN. These six objects are all in our "low luminosity" sample and therefore our conclusions are reinforced: $\sim 30 \%$ of the low luminosity AGN are likely to have somewhat smaller Eddington ratios than our above estimates.

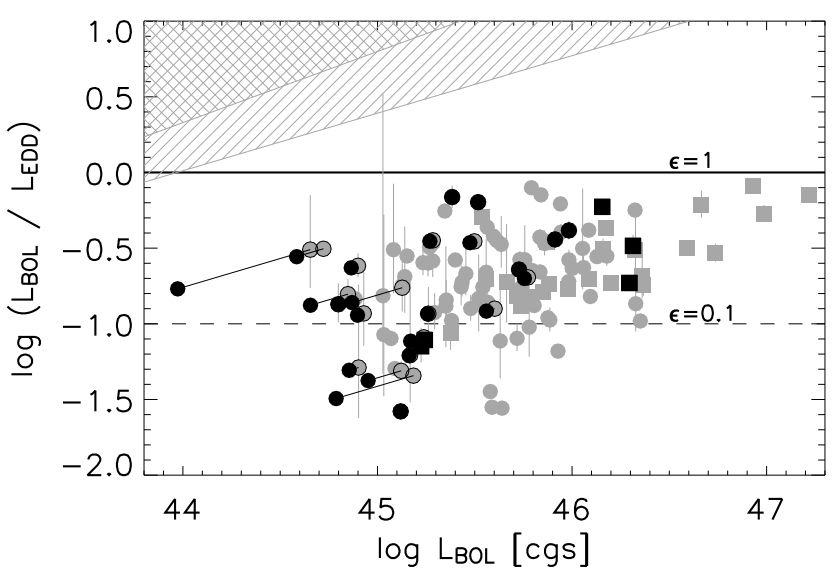

Fig. 3. Effect of host galaxy contamination on the distribution of AGN Eddington ratios versus bolometric luminosities. All points of Fig. 2 are reported in grey with the same symbol convention. Objects for which an estimate of their host galaxy contamination is available are shown with an open black symbol linked to a filled black symbol, corresponding to the position of these objects, respectively before and after correction.

Finally, we verified that the result presented here would have not been significantly different if we had included also the 16 low $S / N$ objects.

\section{Discussion}

\subsection{Comparison with other studies}

Kollmeier et al. (2006) determined black hole masses for a sample of $\sim 400$ AGN with optical magnitudes $R \leq 21.5$, in the context of the AGES survey. Their compilation shows a nearly constant Eddington ratio of $\sim 0.25$, with a dispersion of only $\sim 0.3$ dex, over a wide range of luminosities and redshifts. Our 


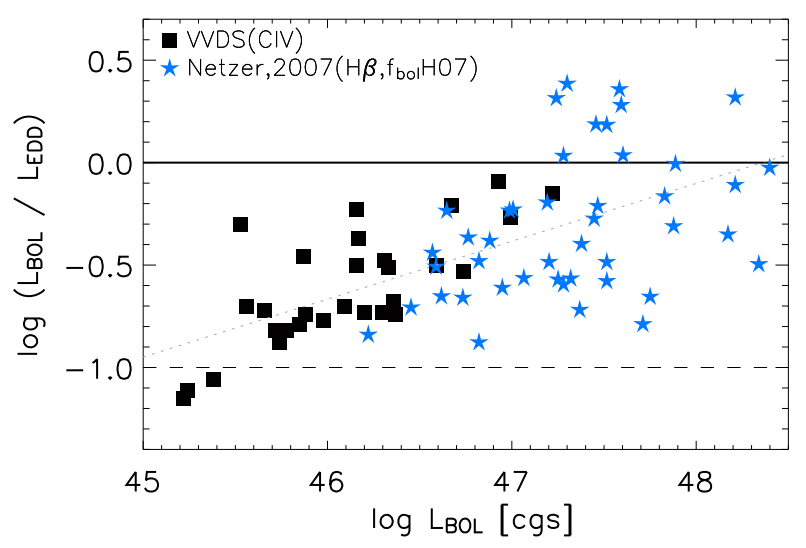

Fig. 4. Distribution of Eddington ratios versus bolometric luminosities of VVDS high redshift and Netzer et al. (2007) sample. For comparison purpose, Eddington ratios and bolometric luminosities of the latter sample have been recomputed with a luminosity dependent correction factor $\left(9.6<f_{\text {bol }}(5100 \AA)<10.5\right.$, Hopkins et al. 2007). The dotted line shows a linear regression relation $\left(\log \epsilon \propto 0.29 \log L_{\text {bol }}\right)$.

lower redshift sample overlaps with their Mg II virial masses in the luminosity range $45 \lesssim \log L_{\text {bol }} \lesssim 46 \mathrm{erg} \mathrm{s}^{-1}$. If we superficially compare their results with ours in this range, we find them to be marginally inconsistent. The probability returned from a KS-test for the two samples to have their Eddington ratios drawn from the same distribution is $P=9 \%$. However, this difference is only caused by the different recipes used to estimate bolometric luminosities and, in particular, black hole masses. If we recompute the $\mathrm{BH}$ masses and bolometric luminosities of the Kollmeier et al. (2006) sample with the same recipes used in the present paper, we find that the two samples are fully consistent with each other.

In particular, Kollmeier et al. (2006) adopted a very steep exponent for the empirical luminosity-size relation for the Mg II emission line, $\gamma=0.88\left(R \propto L^{\gamma}\right)$, whereas we employed $\gamma=0.62$ which is directly taken from the calibration by McLure $\&$ Dunlop (2004). A larger $\gamma$ makes the $L_{\mathrm{bol}}-M_{\mathrm{BH}}$ relation appear steeper and results in smaller $M_{\mathrm{BH}}$ and higher $\epsilon$ values for the lower luminosity AGN.

However, we believe that there are good reasons against such a high value of $\gamma$. Recent reverberation mapping studies (Paltani \& Türler 2005; Kaspi et al. 2007) suggest a rather flat luminosity-size relation also at high luminosities with $\gamma$ even approaching 0.5 (corresponding to an approximately luminosityindependent ionization parameter in the broad-line region of AGN). A low value of $\gamma \sim 0.5$ is also indicated for low redshift AGN after correction for host galaxy contributions (Bentz et al. 2006). Our adopted value of $\gamma=0.62$ may therefore even be considered conservative.

More recently, Netzer et al. (2007) also found a positive trend of $\epsilon$ with luminosity for AGN with redshift 2.3-3.4.

They derived virial black hole masses from the redshifted $\mathrm{H} \beta$ line observed in the near infrared, thus applying directly the reverberation mapping based calibration (although some extrapolation towards high luminosities was required).

Given the match in redshift range, we decided to combine the results by Netzer et al. with our C IV sample. The results are shown in Fig. 4 where, for consistency, we have recomputed the bolometric luminosities and Eddington ratios of the AGN in Netzer's sample using the same bolometric corrections we employed for our data, i.e. applying the Hopkins et al. (2007) luminosity-dependent SED model. The combined sample covers now more than three orders of magnitude in luminosity, with most of our objects being much fainter than those in Netzer's sample. For the luminosity range common to both samples, the values of $\epsilon$ are in very good agreement, despite the fact that we could only use the less trustworthy C IV lines.

Looking at the combined dataset there is again evidence of a correlation of Eddington ratios. In fact, the best-fit regression (dotted line in Fig. 4) returns $\log \epsilon=-0.97+0.28 \log \left(L_{\text {bol }}-\right.$ 45), which is almost indistinguishable from the fit to only the combined VVDS Mg II + C IV sample. Thus the slow increase in Eddington ratios with bolometric luminosities seems to be a remarkably continuous property of high-redshift type 1 AGN, from the very low luminosities of the VVDS AGN to the highly luminous quasars in the sample of Netzer et al. (On the other hand, the dispersion of Eddington ratios in the Netzer sample is larger than in the VVDS, in particular due to the significant number of super-Eddington objects in the former.)

Very recently, Shen et al. (2008) employed a very large sample of SDSS quasar spectra to investigate systematic effects and biases in the derivation of relations between luminosities and black hole masses. They essentially confirm the low apparent dispersion in $\epsilon$ of $\lesssim 0.3$ found already by Kollmeier et al. (2006), however with the exception of their lowest luminosity (and also lowest redshift, $z<1$ ) bin where the dispersion increases to 0.42 dex. Thus, while there is essentially no overlap in the luminosity-redshift plane between SDSS and VVDS, the trends observed in our VVDS sample seems to be consistent with the SDSS results.

Babic et al. (2007) argue that an apparent trend of $\epsilon$ as a function of luminosity is expected if one convolves a double power-law black hole mass function with a relatively broad distribution of Eddington ratios truncated at $\epsilon=1$. We note however that the observed distribution of $\epsilon$ is too symmetric and too narrow for this to be a strong effect: the apparent upper bound of $\epsilon$ evolves along with $L_{\text {bol }}$ from $\log \epsilon<-0.5$ at $\log L_{\text {bol }} \sim 45$ to $\log \epsilon<0.5$ for the high-luminosity objects in the sample by Netzer et al. (2007). In other words, there is no clear evidence of a physical truncation at a fixed $\epsilon$. It is of course still possible that AGN accretion physics imposes some unknown biases on the distribution of Eddington ratios, which may even depend on luminosity or black hole mass, in which case an effect such as described by Babić et al. (2007) may become relevant at some level. Much larger samples and a better understanding of the underlying physical processes would be required to investigate such effects.

\subsection{Relation to the AGN luminosity function}

At fixed redshift, the AGN luminosity function (AGNLF) is generally described as a double power-law. It has now become clear that its shape evolves with redshift, with a marked break for $z>1$ which almost disappears at lower redshift, as the faint-end slope steepens towards later cosmic times (e.g. Hasinger et al. 2005; Hopkins et al. 2007; Bongiorno et al. 2007). The luminous part of the AGNLF is dominated by black holes that appear to be typically accreting close to the Eddington limit $(\epsilon \sim 0.1-1)$, with relatively little dispersion, so that luminosities are roughly proportional to black hole masses, and this part of the AGNLF closely mirrors the black hole mass function.

The flat part of the AGNLF, on the other hand, could be composed of either low mass black holes also accreting close to Eddington, or of high-mass black holes with very low accretion rates, or of a mixture. In the context of a simple model where black hole growth and nuclear activity is triggered by galaxy mergers, Cattaneo (2001) first suggested that the faint 
end slope of the AGNLF could be dominated by objects observed in the decaying phase of their light curve, well past their peak of activity. This idea was recently followed up by numerical simulations of galaxy mergers incorporating AGN feedback. For example Hopkins et al. (2006) find that the observed redshift evolution of the faint-end slope of the AGN luminosity function (flatter at higher redshift) is well reproduced with the luminositydependent quasar lifetime that they derive from extensive numerical simulation of galaxy mergers.

Our observations show that while some of the lowluminosity AGN in our sample have just low $M_{\mathrm{BH}}$, many have instead the properties (i.e. high $M_{\mathrm{BH}}$, low $\epsilon$ ) predicted by these models. This is consistent with the suggested picture in which the faint end of the AGN luminosity function is populated with black holes that have exhausted a substantial fraction of their fuel. We speculate that at these redshifts we see glimpses of a population of AGN with black hole masses similar to those of luminous quasars, but already half starved and on their way to get extinguished.

From an analysis of a heterogeneous sample of low redshift AGN, Woo \& Urry (2002) find that small Eddington ratios are found mainly for AGN with $\log L_{\text {bol }} \leq 44.5$, which in their sample are represented only by local Seyfert galaxies at $z \leq 0.1$ (see their Fig. 8). Comparing their results with our measurements at $z \gtrsim 1$ suggests that the luminosity below which such small Eddington ratios are found may evolve with redshift. This is, at least qualitatively, consistent with the observed redshift evolution of the break of the AGN luminosity function.

\section{Conclusions}

The VVDS is the first large spectroscopic AGN survey to probe luminosities as low as $\log L_{\text {bol }} \lesssim 45$ at redshifts $z>1$. We estimated black hole masses and Eddington ratios for $120 \mathrm{AGN}$. The main result of our study is a marked increase in the dispersion in Eddington ratios towards lower AGN bolometric luminosities. A substantial fraction of black holes in low- $L$ AGN accretes at less than $10 \%$ of their Eddington limits, whereas such low accretors are rare among AGN with higher $L$.

Our data also suggest that on average, the Eddington ratios systematically increase with nuclear luminosity. In the presence of substantial scatter and limited luminosity coverage, this trend is not easy to quantify; the slope of a relation $\epsilon \propto L^{\alpha}$ depends on the adopted exponent in the empirical luminosity-size relation needed for virial scaling relations. Tentatively combining our data with those of Netzer et al. (2007), however, leads to fully consistent results and underlines the indicated trend of $\epsilon$ increasing with $L_{\mathrm{bol}}$.

It is currently widely discussed how accurate the black hole masses and Eddington ratios based on single-epoch spectra can be. The best line is clearly $\mathrm{H} \beta$ as here the luminosity-size relation has been directly calibrated with reverberation mapping. $\mathrm{Mg}$ II-based estimates can be cross-calibrated with $\mathrm{H} \beta$ measurements and correlate quite well (McLure \& Jarvis 2002; Shen et al. 2008). The C IV line, on the other hand, is under suspicion of representing gas that is not necessarily in or even close to virial equilibrium. One strong indication for such nongravitational effects is the systematic blueshift of C IV with respect to low ionization lines (Gaskell 1982; Tytler \& Fan 1992), which in combination with often asymmetric profiles (Richards et al. 2002) can be interpreted as the result of obscuration or radiative pressure. Consequently, the C IV emission line is often considered as not well suited to estimate black hole masses. Baskin \& Laor (2005) and Netzer et al. (2007) found only a weak correlation between virial black hole mass estimates based on $\mathrm{H} \beta$ and C IV. Similarly, Shen et al. (2008) noted a much tighter correlation between $\mathrm{H} \beta$ and $\mathrm{Mg}$ II than between $\mathrm{Mg}$ II and C IV. For our VVDS sample, however, the observed trends between $\mathrm{Mg}$ II and C IV based subsamples (and also the $\mathrm{H} \beta$ sample by Netzer et al. 2007) are highly consistent. In fact, the observed scatter in the $L_{\text {bol }}-\epsilon$ relation is lower for the C IV objects than for the $\mathrm{Mg}$ II ones. It may be that radiation pressure and outflows are relevant in particular for high-luminosity QSOs (as has been also suggested by Marconi et al. 2008), and that therefore virial mass estimates based on C IV are more reliable for the faint AGN sampled in the VVDS than for other surveys.

While the "virial estimator" is likely to remain for some time the only practical method to obtain statistics on black hole masses at substantial redshifts, the present dependency of all measurements on the small number of low- $z$ reverberationmapped AGN is unsatisfactory. It would be highly desirable if directly calibrated luminosity-size relations could be established also for higher redshifts and other lines than $\mathrm{H} \beta$.

Acknowledgements. We thank the referee, Marco Salvati, for his constructive comments that have led to improve this publication. We are grateful to Marianne Vestergaard for providing us with her UV Fe II templates, as well as to Juna Kollmeier and Hagai Netzer for communicating us the data table of their publications for our comparison purpose. We thank Suzy Collin and Asmus Böhm for helpful discussions.

\section{Appendix A: Mbh tables}

Table A.1. Black hole masses and Eddington ratios estimated from the Mg II emission line.

\begin{tabular}{ccccccccr}
\hline \hline $\begin{array}{c}\text { Object ID } \\
(1)\end{array}$ & $\begin{array}{c}z \\
(2)\end{array}$ & $\begin{array}{c}I_{\mathrm{AB}} \\
(3)\end{array}$ & \multicolumn{1}{c}{$S / N$} & \multicolumn{1}{c}{$\log \lambda L_{3000}$} & \multicolumn{1}{c}{$\log L_{\mathrm{bol}}$} & $F W H M$ & $\begin{array}{r}\log \frac{M_{\mathrm{BH}}}{M_{\odot}} \\
(5)\end{array}$ & $\begin{array}{r}\log \epsilon \\
(6)\end{array}$ \\
\hline 220551387 & 1.881 & 21.55 & 11.5 & 45.00 & 45.83 & 3277 & 8.16 & -0.43 \\
140265284 & 1.855 & 21.45 & 16.7 & 44.89 & 45.73 & 3730 & 8.21 & -0.58 \\
220082140 & 1.848 & 20.68 & 18.2 & 45.23 & 46.05 & 3903 & 8.46 & -0.50 \\
100113463 & 1.844 & 20.52 & 34.0 & 45.27 & 46.09 & 5720 & 8.81 & -0.82 \\
220090821 & 1.833 & 20.49 & 15.5 & 45.26 & 46.09 & 3442 & 8.37 & -0.38 \\
140520998 & 1.829 & 20.89 & 26.5 & 45.06 & 45.89 & 6286 & 8.76 & -0.98 \\
140363408 & 1.826 & 21.87 & 11.3 & 44.97 & 45.81 & 5448 & 8.58 & -0.88 \\
100110223 & 1.826 & 21.35 & 7.9 & 44.92 & 45.76 & 3770 & 8.23 & -0.58 \\
140495178 & 1.824 & 20.80 & 29.6 & 45.24 & 46.06 & 4525 & 8.59 & -0.63 \\
020461459 & 1.821 & 21.60 & 20.8 & 44.89 & 45.73 & 4016 & 8.27 & -0.64 \\
220308643 & 1.801 & 21.89 & 11.2 & 44.79 & 45.63 & 6649 & 8.64 & -1.11 \\
\hline
\end{tabular}


Table A.1. continued.

\begin{tabular}{|c|c|c|c|c|c|c|c|c|}
\hline $\begin{array}{c}\text { Object ID } \\
\text { (1) }\end{array}$ & $\begin{array}{c}z \\
(2)\end{array}$ & $\begin{array}{l}I_{\mathrm{AB}} \\
(3)\end{array}$ & $\begin{array}{c}S / N \\
(4)\end{array}$ & $\begin{array}{c}\log \lambda L_{3000} \\
(5)\end{array}$ & $\begin{array}{c}\log L_{\text {bol }} \\
\text { (6) }\end{array}$ & $\begin{array}{c}F W H M \\
\text { (7) }\end{array}$ & $\begin{array}{c}\log \frac{M_{\mathrm{BH}}}{M_{\odot}} \\
\text { (8) }\end{array}$ & $\begin{array}{r}\log \epsilon \\
(9)\end{array}$ \\
\hline 100122852 & 1.801 & 19.90 & 54.1 & 45.52 & 46.33 & 6649 & 9.09 & -0.87 \\
\hline 100507363 & 1.784 & 21.69 & 14.1 & 44.79 & 45.64 & 3195 & 8.01 & -0.47 \\
\hline 100451895 & 1.781 & 20.08 & 28.9 & 45.51 & 46.32 & 3257 & 8.47 & -0.25 \\
\hline 220438495 & 1.774 & 21.93 & 10.7 & 44.67 & 45.52 & 4606 & 8.25 & -0.83 \\
\hline 100232259 & 1.765 & 21.13 & 10.2 & 44.88 & 45.72 & 6749 & 8.71 & -1.10 \\
\hline 140433507 & 1.765 & 21.13 & 13.2 & 44.95 & 45.78 & 6356 & 8.70 & -1.02 \\
\hline 020278210 & 1.757 & 21.36 & 26.4 & 44.76 & 45.60 & 5144 & 8.40 & -0.90 \\
\hline 020254511 & 1.747 & 20.66 & 49.8 & 45.08 & 45.91 & 3442 & 8.26 & -0.44 \\
\hline 220370320 & 1.745 & 20.22 & 25.2 & 45.36 & 46.18 & 4352 & 8.63 & -0.55 \\
\hline 220409734 & 1.742 & 21.90 & 10.2 & 44.77 & 45.61 & 3071 & 7.96 & -0.45 \\
\hline 220159199 & 1.722 & 22.12 & 9.1 & 44.58 & 45.43 & 4067 & 8.09 & -0.76 \\
\hline 020177875 & 1.682 & 22.53 & 8.0 & 44.32 & 45.18 & 7263 & 8.43 & -1.34 \\
\hline 220427244 & 1.681 & 20.40 & 16.5 & 45.31 & 46.13 & 4281 & 8.58 & -0.56 \\
\hline 220371301 & 1.645 & 22.18 & 12.2 & 44.72 & 45.57 & 4830 & 8.32 & -0.86 \\
\hline 020232397 & 1.628 & 22.69 & 11.2 & 44.25 & 45.13 & 3637 & 7.79 & -0.76 \\
\hline 000033629 & 1.621 & 22.14 & 14.7 & 44.50 & 45.35 & 4362 & 8.10 & -0.84 \\
\hline 020114448 & 1.614 & 22.24 & 8.5 & 44.37 & 45.24 & 5539 & 8.23 & -1.09 \\
\hline 020120394 & 1.612 & 20.38 & 64.6 & 45.16 & 45.98 & 3308 & 8.27 & -0.38 \\
\hline 020466135 & 1.581 & 21.13 & 63.6 & 44.94 & 45.77 & 4342 & 8.37 & -0.69 \\
\hline 020147295 & 1.556 & 22.59 & 14.0 & 44.30 & 45.17 & 6175 & 8.28 & -1.21 \\
\hline 100290682 & 1.549 & 21.49 & 17.7 & 44.75 & 45.60 & 2957 & 7.92 & -0.42 \\
\hline 220566905 & 1.528 & 22.38 & 13.9 & 44.49 & 45.35 & 2211 & 7.50 & -0.25 \\
\hline 020210524 & 1.515 & 20.41 & 82.2 & 45.18 & 46.00 & 4444 & 8.53 & -0.63 \\
\hline 220610034 & 1.513 & 20.66 & 42.3 & 45.12 & 45.94 & 3298 & 8.24 & -0.39 \\
\hline 020176565 & 1.504 & 23.24 & 11.5 & 44.01 & 44.90 & 2822 & 7.42 & -0.62 \\
\hline 220327763 & 1.501 & 21.36 & 36.2 & 44.96 & 45.80 & 4159 & 8.34 & -0.65 \\
\hline 220568559 & 1.498 & 22.21 & 12.3 & 44.49 & 45.35 & 4566 & 8.13 & -0.88 \\
\hline 220609820 & 1.479 & 21.64 & 18.9 & 44.71 & 45.56 & 3832 & 8.12 & -0.66 \\
\hline 220419246 & 1.479 & 20.73 & 20.2 & 45.05 & 45.88 & 6155 & 8.74 & -0.96 \\
\hline 220376198 & 1.469 & 21.75 & 18.5 & 44.63 & 45.48 & 4891 & 8.28 & -0.90 \\
\hline 220377744 & 1.465 & 21.18 & 15.4 & 44.80 & 45.64 & 11129 & 9.10 & -1.56 \\
\hline 100046262 & 1.463 & 20.96 & 39.1 & 44.93 & 45.76 & 5255 & 8.53 & -0.86 \\
\hline 220469918 & 1.460 & 21.89 & 11.2 & 44.40 & 45.27 & 2822 & 7.66 & -0.49 \\
\hline 140338689 & 1.442 & 20.74 & 37.6 & 44.96 & 45.79 & 2211 & 7.79 & -0.10 \\
\hline 140441955 & 1.429 & 22.06 & 16.6 & 44.58 & 45.43 & 3934 & 8.06 & -0.73 \\
\hline 020367106 & 1.397 & 22.42 & 10.7 & 44.19 & 45.07 & 5235 & 8.07 & -1.10 \\
\hline 220326578 & 1.391 & 22.23 & 11.6 & 44.28 & 45.15 & 2884 & 7.60 & -0.55 \\
\hline 020463196 & 1.388 & 23.27 & 8.5 & 43.74 & 44.65 & 2275 & 7.06 & -0.51 \\
\hline 020179225 & 1.386 & 22.39 & 28.5 & 44.25 & 45.12 & 9293 & 8.60 & -1.58 \\
\hline 140305471 & 1.370 & 21.08 & 16.5 & 44.69 & 45.54 & 4261 & 8.20 & -0.76 \\
\hline 220554600 & 1.369 & 20.78 & 27.6 & 44.91 & 45.74 & 4606 & 8.40 & -0.76 \\
\hline 020467628 & 1.358 & 21.35 & 30.7 & 44.65 & 45.50 & 2957 & 7.85 & -0.46 \\
\hline 020258622 & 1.339 & 22.74 & 16.1 & 44.04 & 44.93 & 4097 & 7.76 & -0.93 \\
\hline 100198426 & 1.337 & 22.14 & 9.5 & 44.15 & 45.03 & 3719 & 7.74 & -0.81 \\
\hline 220093875 & 1.337 & 21.94 & 10.0 & 44.37 & 45.23 & 3133 & 7.73 & -0.60 \\
\hline 020165108 & 1.322 & 23.09 & 9.6 & 43.82 & 44.72 & 2317 & 7.13 & -0.50 \\
\hline 020163018 & 1.321 & 23.11 & 13.3 & 43.95 & 44.85 & 3432 & 7.55 & -0.80 \\
\hline 220542377 & 1.310 & 21.24 & 24.5 & 44.73 & 45.58 & 9574 & 8.93 & -1.45 \\
\hline 140222324 & 1.305 & 21.72 & 20.0 & 44.42 & 45.28 & 2759 & 7.65 & -0.47 \\
\hline 220525793 & 1.294 & 19.13 & 98.3 & 45.54 & 46.35 & 7655 & 9.23 & -0.98 \\
\hline 220247296 & 1.285 & 21.52 & 22.2 & 44.52 & 45.38 & 5154 & 8.26 & -0.98 \\
\hline 020118483 & 1.261 & 22.86 & 12.0 & 43.90 & 44.80 & 3637 & 7.57 & -0.87 \\
\hline 000028880 & 1.257 & 22.71 & 18.5 & 43.99 & 44.89 & 3607 & 7.62 & -0.83 \\
\hline 220613346 & 1.253 & 20.51 & 37.4 & 45.00 & 45.84 & 4271 & 8.39 & -0.66 \\
\hline 100139500 & 1.248 & 21.01 & 20.1 & 44.71 & 45.56 & 4911 & 8.33 & -0.88 \\
\hline 020213000 & 1.225 & 21.44 & 20.7 & 44.40 & 45.26 & 4667 & 8.09 & -0.93 \\
\hline 220081925 & 1.217 & 21.79 & 11.9 & 44.42 & 45.28 & 3154 & 7.77 & -0.58 \\
\hline 020237445 & 1.214 & 22.43 & 8.0 & 44.01 & 44.90 & 6124 & 8.09 & -1.29 \\
\hline 220375302 & 1.208 & 21.82 & 13.1 & 44.43 & 45.29 & 4688 & 8.12 & -0.93 \\
\hline 140433055 & 1.208 & 22.33 & 27.0 & 44.27 & 45.14 & 3360 & 7.73 & -0.69 \\
\hline
\end{tabular}


Table A.1. continued.

\begin{tabular}{|c|c|c|c|c|c|c|c|c|}
\hline $\begin{array}{c}\text { Object ID } \\
\text { (1) }\end{array}$ & $\begin{array}{c}z \\
(2)\end{array}$ & $\begin{array}{l}I_{\mathrm{AB}} \\
(3)\end{array}$ & $\begin{array}{l}S / N \\
(4)\end{array}$ & $\begin{array}{c}\log \lambda L_{3000} \\
(5)\end{array}$ & $\begin{array}{c}\log L_{\text {bol }} \\
\text { (6) }\end{array}$ & $\begin{array}{c}F W H M \\
\text { (7) }\end{array}$ & $\begin{array}{c}\log \frac{M_{\mathrm{BH}}}{M_{\odot}} \\
(8)\end{array}$ & $\begin{array}{r}\log \epsilon \\
(9)\end{array}$ \\
\hline 100048462 & 1.203 & 20.48 & 42.5 & 44.91 & 45.75 & 5093 & 8.49 & -0.84 \\
\hline 220255701 & 1.193 & 19.77 & 63.9 & 45.11 & 45.94 & 2655 & 8.05 & -0.21 \\
\hline 020086859 & 1.192 & 20.97 & 27.7 & 44.67 & 45.52 & 2211 & 7.61 & -0.20 \\
\hline 140306523 & 1.190 & 20.10 & 60.6 & 45.16 & 45.98 & 4880 & 8.60 & -0.72 \\
\hline 100210521 & 1.172 & 21.63 & 18.8 & 44.40 & 45.26 & 3174 & 7.76 & -0.60 \\
\hline 220567825 & 1.160 & 21.19 & 23.8 & 44.72 & 45.56 & 2728 & 7.83 & -0.36 \\
\hline 100338914 & 1.158 & 19.78 & 57.2 & 45.16 & 45.98 & 4138 & 8.46 & -0.58 \\
\hline 020364478 & 1.157 & 21.74 & 25.5 & 44.25 & 45.12 & 6830 & 8.33 & -1.31 \\
\hline 140192158 & 1.127 & 22.12 & 17.1 & 44.15 & 45.03 & 5012 & 8.00 & -1.07 \\
\hline 220561414 & 1.124 & 20.11 & 49.8 & 45.01 & 45.84 & 2381 & 7.89 & -0.15 \\
\hline 220357650 & 1.123 & 22.34 & 14.2 & 44.21 & 45.08 & 2675 & 7.49 & -0.51 \\
\hline 020243922 & 1.120 & 21.29 & 44.8 & 44.42 & 45.28 & 2696 & 7.63 & -0.45 \\
\hline 140443623 & 1.120 & 21.48 & 16.7 & 44.26 & 45.13 & 3555 & 7.77 & -0.74 \\
\hline 100241696 & 1.111 & 22.00 & 11.3 & 44.21 & 45.09 & 6628 & 8.29 & -1.30 \\
\hline 220458211 & 1.105 & 20.69 & 36.8 & 45.03 & 45.86 & 3473 & 8.23 & -0.47 \\
\hline 220463317 & 1.066 & 19.62 & 43.8 & 45.10 & 45.93 & 8098 & 9.01 & -1.18 \\
\hline 020329650 & 1.050 & 20.84 & 36.0 & 44.53 & 45.38 & 2018 & 7.45 & -0.16 \\
\hline 140278593 & 1.046 & 20.50 & 36.7 & 44.74 & 45.59 & 10828 & 9.04 & -1.55 \\
\hline 220152300 & 1.038 & 20.69 & 19.2 & 44.54 & 45.40 & 3277 & 7.88 & -0.58 \\
\hline 220586430 & 1.028 & 20.45 & 26.8 & 44.60 & 45.45 & 3719 & 8.02 & -0.67 \\
\hline
\end{tabular}

Table columns: (1) Object identification number of the VVDS database. (2) Redshift. (3) $I$ magnitudes in the AB system. (4) Mean $S / N$ per pixel in the vicinity of the broad-emission line. (5) Monochromatic luminosity at $3000 \AA$ in $\mathrm{erg} \mathrm{s}^{-1}$. (6) Corresponding bolometric luminosity in erg s ${ }^{-1}$. (7) $F W H M$ of the $\mathrm{Mg}$ II in $\mathrm{km} \mathrm{s}^{-1}$. (8) Estimate of the virial black hole Mass as obtained from Eq. (1). (9) Eddington ratio.

Table A.2. Black hole masses and Eddington ratios estimated from the C IV emission line.

\begin{tabular}{ccccccccr}
\hline \hline Object ID & $z$ & $I_{\mathrm{AB}}$ & \multicolumn{1}{c}{$S / N$} & $\log \lambda L_{1350}$ & $\log L_{\text {bol }}$ & $\sigma$ & $\log \frac{M_{\mathrm{BH}}}{M_{\odot}}$ & $\begin{array}{r}\log \epsilon \\
(1)\end{array}$ \\
$(2)$ & \multicolumn{1}{c}{$(3)$} & \multicolumn{1}{c}{$(4)$} & \multicolumn{1}{c}{$(5)$} & \multicolumn{1}{c}{$(6)$} & $(7)$ & $(8)$ & $(9)$ \\
\hline 220183694 & 4.193 & 20.27 & 33.1 & 46.34 & 46.93 & 2976 & 8.92 & -0.09 \\
020254576 & 3.853 & 21.15 & 35.5 & 45.71 & 46.31 & 3406 & 8.70 & -0.48 \\
220267678 & 3.833 & 21.44 & 11.9 & 45.72 & 46.33 & 3534 & 8.74 & -0.51 \\
020277536 & 3.626 & 23.55 & 16.7 & 44.58 & 45.24 & 4032 & 8.25 & -1.11 \\
220055529 & 3.594 & 21.52 & 9.6 & 45.76 & 46.37 & 4708 & 9.01 & -0.74 \\
100471137 & 3.494 & 20.12 & 39.6 & 46.07 & 46.67 & 2994 & 8.78 & -0.21 \\
020179116 & 3.308 & 23.89 & 10.4 & 44.56 & 45.22 & 4191 & 8.27 & -1.15 \\
140465826 & 3.290 & 20.16 & 60.3 & 46.14 & 46.74 & 4486 & 9.17 & -0.53 \\
020465339 & 3.285 & 21.09 & 65.2 & 45.69 & 46.30 & 4476 & 8.93 & -0.73 \\
100049642 & 3.192 & 20.55 & 41.7 & 45.75 & 46.36 & 4385 & 8.94 & -0.68 \\
140191403 & 3.170 & 22.15 & 19.1 & 45.36 & 45.98 & 3988 & 8.65 & -0.77 \\
220359141 & 3.158 & 22.64 & 10.5 & 44.72 & 45.38 & 4079 & 8.33 & -1.06 \\
220157547 & 3.152 & 22.26 & 8.1 & 45.03 & 45.66 & 3211 & 8.29 & -0.72 \\
220133794 & 3.147 & 22.29 & 17.9 & 45.24 & 45.87 & 2623 & 8.23 & -0.46 \\
220617869 & 3.133 & 22.36 & 12.8 & 45.08 & 45.72 & 3673 & 8.43 & -0.82 \\
220309346 & 3.090 & 22.22 & 21.8 & 45.10 & 45.74 & 3987 & 8.52 & -0.88 \\
220391155 & 3.087 & 21.07 & 31.5 & 45.56 & 46.17 & 2759 & 8.44 & -0.37 \\
100245809 & 3.079 & 21.67 & 19.1 & 45.25 & 45.88 & 3650 & 8.52 & -0.74 \\
220205172 & 3.076 & 19.17 & 83.7 & 46.40 & 46.99 & 3789 & 9.16 & -0.27 \\
220133609 & 3.051 & 20.40 & 39.7 & 45.99 & 46.59 & 3994 & 8.99 & -0.50 \\
220056847 & 3.001 & 21.47 & 26.4 & 45.59 & 46.20 & 4275 & 8.83 & -0.73 \\
220044408 & 2.910 & 21.28 & 17.4 & 45.15 & 45.78 & 3806 & 8.50 & -0.82 \\
140493205 & 2.865 & 21.66 & 24.2 & 45.23 & 45.85 & 3821 & 8.54 & -0.79 \\
220181962 & 2.856 & 18.72 & 125.1 & 46.64 & 47.22 & 3706 & 9.26 & -0.15 \\
140040016 & 2.838 & 21.55 & 39.8 & 45.47 & 46.09 & 3896 & 8.69 & -0.70 \\
140432542 & 2.800 & 21.85 & 17.2 & 45.55 & 46.16 & 3210 & 8.56 & -0.50 \\
020268754 & 2.719 & 20.59 & 63.0 & 45.54 & 46.16 & 2332 & 8.28 & -0.23 \\
100168207 & 2.715 & 22.46 & 24.4 & 44.89 & 45.53 & 1840 & 7.73 & -0.30 \\
220001963 & 2.680 & 22.28 & 13.5 & 44.92 & 45.56 & 2968 & 8.16 & -0.70 \\
\hline
\end{tabular}

Table columns: (1) Object identification number of the VVDS database. (2) Redshift. (3) $I$ magnitudes in the AB system. (4) Mean $S / N$ per pixel in the vicinity of the broad-emission line. (5) Monochromatic luminosity at $1350 \AA$ in $\mathrm{erg} \mathrm{s}^{-1}$. (6) Corresponding bolometric luminosity in erg s $\mathrm{s}^{-1}$. (7) Emission line velocity dispersion, $\sigma$ of the $\mathrm{CIV}$ in $\mathrm{km} \mathrm{s}^{-1}$. (8) Estimate of the virial black hole Mass as obtained from Eq. (2). (9) Eddington ratio. 
Appendix B: Catalog of VVDS broad-line AGN (first and second-epoch data)

Table B.1. Catalog of broad-line AGN with secure redshift.

\begin{tabular}{|c|c|c|c|c|c|c|c|c|c|c|c|}
\hline $\begin{array}{c}\text { Object ID } \\
\text { (1) }\end{array}$ & $\begin{array}{c}\alpha_{J 2000} \\
(2)\end{array}$ & $\begin{array}{c}\delta_{J 2000} \\
(3)\end{array}$ & $\begin{array}{c}z \\
(4)\end{array}$ & $\begin{array}{r}\text { Flag } \\
(5)\end{array}$ & $\begin{array}{c}\text { Epoch } \\
\text { (6) }\end{array}$ & $\begin{array}{l}B_{\mathrm{AB}} \\
(7)\end{array}$ & $\begin{array}{l}V_{\mathrm{AB}} \\
(8)\end{array}$ & $\begin{array}{l}R_{\mathrm{AB}} \\
(9)\end{array}$ & $\begin{array}{l}I_{\mathrm{AB}} \\
(10)\end{array}$ & $\begin{array}{l}\text { Morphology } \\
\text { (11) }\end{array}$ & $\begin{array}{c}\text { Remark } \\
\text { (12) }\end{array}$ \\
\hline CDFS: & Deep mode & $10 \mathrm{AGN}$ & & & & & & & & & \\
\hline 000018607 & $03^{\mathrm{h}} 32^{\mathrm{m}} 18.26^{\mathrm{s}}$ & $-27^{\circ} 52^{\mathrm{m}} 41.42^{\mathrm{s}}$ & 2.8010 & 14 & 1 & 23.94 & 24.62 & 24.08 & 23.91 & & . \\
\hline 000025363 & $03^{\mathrm{h}} 32^{\mathrm{m}} 59.85^{\mathrm{s}}$ & $-27^{\circ} 47^{\mathrm{m}} 48.42^{\mathrm{s}}$ & 2.5673 & 14 & 1 & 22.09 & 21.66 & 21.92 & 21.95 & & \\
\hline 000023526 & $03^{\mathrm{h}} 32^{\mathrm{m}} 43.25^{\mathrm{s}}$ & $-27^{\circ} 49^{\mathrm{m}} 14.38^{\mathrm{s}}$ & 1.9199 & 14 & 1 & 22.53 & 22.70 & 22.65 & 22.17 & & Sz. \\
\hline 000033629 & $03^{\mathrm{h}} 32^{\mathrm{m}} 25.17^{\mathrm{s}}$ & $-27^{\circ} 42^{\mathrm{m}} 19.05^{\mathrm{s}}$ & 1.6207 & 14 & 1 & 24.33 & 23.90 & 22.94 & 22.14 & & $\ldots$ \\
\hline 000073509 & $03^{\mathrm{h}} 32^{\mathrm{m}} 02.47^{\mathrm{s}}$ & $-27^{\circ} 46^{\mathrm{m}} 00.53^{\mathrm{s}}$ & 1.6199 & 14 & 1 & 25.34 & 24.59 & 23.95 & 23.62 & & Sz. \\
\hline 000028880 & $03^{\mathrm{h}} 33^{\mathrm{m}} 03.62^{\mathrm{s}}$ & $-27^{\circ} 45^{\mathrm{m}} 18.97^{\mathrm{s}}$ & 1.2574 & 14 & 1 & 23.78 & 23.30 & 22.98 & 22.71 & & Sz. \\
\hline 000031947 & $03^{\mathrm{h}} 32^{\mathrm{m}} 00.37^{\mathrm{s}}$ & $-27^{\circ} 43^{\mathrm{m}} 19.85^{\mathrm{s}}$ & 1.0401 & 14 & 1 & 22.99 & 22.25 & 22.13 & 22.12 & & Sz. \\
\hline 000037399 & $03^{\mathrm{h}} 32^{\mathrm{m}} 38.14^{\mathrm{s}}$ & $-27^{\circ} 39^{\mathrm{m}} 45.02^{\mathrm{s}}$ & 0.8366 & 14 & 1 & 20.84 & 20.43 & 20.41 & 20.44 & & $\ldots$ \\
\hline 000029274 & $03^{\mathrm{h}} 32^{\mathrm{m}} 30.23^{\mathrm{s}}$ & $-27^{\circ} 45^{\mathrm{m}} 04.75^{\mathrm{s}}$ & 0.7352 & 14 & 1 & 22.67 & 22.30 & 22.05 & 21.62 & & \\
\hline 000037103 & $03^{\mathrm{h}} 32^{\mathrm{m}} 37.47^{\mathrm{s}}$ & $-27^{\circ} 40^{\mathrm{m}} 00.33^{\mathrm{s}}$ & 0.6656 & 14 & 1 & 23.11 & 22.93 & 22.46 & 21.84 & & $\ldots$ \\
\hline $0226-04$ & Deep mode & $58 \mathrm{AGN}$ & & & & & & & & & \\
\hline 020254576 & $02^{\mathrm{h}} 25^{\mathrm{m}} 27.23^{\mathrm{s}}$ & $-04^{\circ} 26^{\mathrm{m}} 31.02^{\mathrm{s}}$ & 3.8527 & 14 & 1 & 23.35 & 21.80 & 21.46 & 21.15 & point-like & $\ldots$ \\
\hline 020277536 & $02^{\mathrm{h}} 27^{\mathrm{m}} 53.85^{\mathrm{s}}$ & $-04^{\circ} 23^{\mathrm{m}} 20.10^{\mathrm{s}}$ & 3.6260 & 14 & 1 & 25.26 & 23.89 & 23.61 & 23.56 & & \\
\hline 020169816 & $02^{\mathrm{h}} 25^{\mathrm{m}} 45.04^{\mathrm{s}}$ & $-04^{\circ} 37^{\mathrm{m}} 35.95^{\mathrm{s}}$ & 3.5893 & 14 & 1 & 24.67 & 22.96 & 22.65 & 22.15 & point-like & FORS \\
\hline 020351846 & $02^{\mathrm{h}} 26^{\mathrm{m}} 30.84^{\mathrm{s}}$ & $-04^{\circ} 13^{\mathrm{m}} 26.09^{\mathrm{s}}$ & 3.5680 & 14 & 1 & 25.06 & 23.71 & 23.24 & 22.80 & & FORS \\
\hline 020467962 & $02^{\mathrm{h}} 26^{\mathrm{m}} 59.17^{\mathrm{s}}$ & $-04^{\circ} 16^{\mathrm{m}} 55.89^{\mathrm{s}}$ & 3.3247 & 13 & 1 & 25.23 & 23.97 & 23.80 & 23.59 & & $\ldots$ \\
\hline 020179116 & $02^{\mathrm{h}} 25^{\mathrm{m}} 34.98^{\mathrm{s}}$ & $-04^{\circ} 36^{\mathrm{m}} 16.46^{\mathrm{s}}$ & 3.3080 & 14 & 1 & 25.19 & 23.95 & 23.85 & 23.90 & & FORS \\
\hline 020118986 & $02^{\mathrm{h}} 26^{\mathrm{m}} 54.53^{\mathrm{s}}$ & $-04^{\circ} 44^{\mathrm{m}} 37.72^{\mathrm{s}}$ & 3.3018 & 14 & 1 & 25.43 & 23.99 & 23.98 & 23.58 & $\ldots$ & $\ldots$ \\
\hline 020465339 & $02^{\mathrm{h}} 27^{\mathrm{m}} 06.44^{\mathrm{s}}$ & $-04^{\circ} 19^{\mathrm{m}} 24.30^{\mathrm{s}}$ & 3.2852 & 14 & 1 & 21.78 & 21.32 & 21.00 & 21.10 & point-like & $\ldots$ \\
\hline 020461765 & $02^{\mathrm{h}} 26^{\mathrm{m}} 35.95^{\mathrm{s}}$ & $-04^{\circ} 23^{\mathrm{m}} 21.81^{\mathrm{s}}$ & 3.2831 & 14 & 1 & 24.62 & 23.01 & 22.87 & 22.89 & & $\ldots$ \\
\hline 020180665 & $02^{\mathrm{h}} 26^{\mathrm{m}} 45.46^{\mathrm{s}}$ & $-04^{\circ} 36^{\mathrm{m}} 15.43^{\mathrm{s}}$ & 3.2619 & 14 & 1 & 21.09 & 19.32 & 19.03 & 18.15 & point-like & $\ldots$ \\
\hline 020164607 & $02^{\mathrm{h}} 25^{\mathrm{m}} 32.46^{\mathrm{s}}$ & $-04^{\circ} 38^{\mathrm{m}} 18.63^{\mathrm{s}}$ & 2.9220 & 14 & 1 & 23.93 & 23.46 & 23.21 & 23.11 & $\ldots$ & $\ldots$ \\
\hline 020205812 & $02^{\mathrm{h}} 27^{\mathrm{m}} 23.84^{\mathrm{s}}$ & $-04^{\circ} 32^{\mathrm{m}} 31.69^{\mathrm{s}}$ & 2.8922 & 14 & 1 & 24.77 & 24.37 & 24.52 & 23.87 & $\ldots$ & $\ldots$ \\
\hline 020131908 & $02^{\mathrm{h}} 26^{\mathrm{m}} 51.04^{\mathrm{s}}$ & $-04^{\circ} 42^{\mathrm{m}} 56.55^{\mathrm{s}}$ & 2.7813 & 14 & 1 & 23.09 & 22.76 & 22.77 & 22.34 & extended & $\ldots$ \\
\hline 020200020 & $02^{\mathrm{h}} 25^{\mathrm{m}} 50.40^{\mathrm{s}}$ & $-04^{\circ} 33^{\mathrm{m}} 24.00^{\mathrm{s}}$ & 2.7373 & 13 & 1 & 21.96 & 22.10 & 21.73 & 21.92 & point-like & $\ldots$ \\
\hline 020465540 & $02^{\mathrm{h}} 26^{\mathrm{m}} 44.48^{\mathrm{s}}$ & $-04^{\circ} 19^{\mathrm{m}} 16.76^{\mathrm{s}}$ & 2.7372 & 14 & 1 & 24.15 & 23.95 & 23.82 & 23.58 & $\ldots$ & $\ldots$ \\
\hline 020268754 & $02^{\mathrm{h}} 26^{\mathrm{m}} 09.63^{\mathrm{s}}$ & $-04^{\circ} 24^{\mathrm{m}} 37.74^{\mathrm{s}}$ & 2.7187 & 14 & 1 & 20.57 & 20.60 & 20.76 & 20.59 & point-like & $\ldots$ \\
\hline 020272573 & $02^{\mathrm{h}} 26^{\mathrm{m}} 26.13^{\mathrm{s}}$ & $-04^{\circ} 24^{\mathrm{m}} 03.19^{\mathrm{s}}$ & 2.6823 & 14 & 1 & 24.30 & 23.93 & 23.59 & 23.63 & $\ldots$ & $\ldots$ \\
\hline 020195823 & $02^{\mathrm{h}} 27^{\mathrm{m}} 24.10^{\mathrm{s}}$ & $-04^{\circ} 33^{\mathrm{m}} 55.72^{\mathrm{s}}$ & 2.4250 & 14 & 1 & 24.20 & 23.62 & 23.85 & 23.38 & & FORS \\
\hline 020239945 & $02^{\mathrm{h}} 27^{\mathrm{m}} 31.14^{\mathrm{s}}$ & $-04^{\circ} 28^{\mathrm{m}} 22.83^{\mathrm{s}}$ & 2.4247 & 14 & 1 & 23.66 & 23.13 & 23.14 & 22.90 & & FORS \\
\hline 020208084 & $02^{\mathrm{h}} 27^{\mathrm{m}} 29.24^{\mathrm{s}}$ & $-04^{\circ} 32^{\mathrm{m}} 27.51^{\mathrm{s}}$ & 2.2850 & 214 & 1 & 19.34 & 19.10 & 19.12 & 19.04 & point-like & FORS \\
\hline 020302785 & $02^{\mathrm{h}} 26^{\mathrm{m}} 24.63^{\mathrm{s}}$ & $-04^{\circ} 20^{\mathrm{m}} 02.14^{\mathrm{s}}$ & 2.2357 & 14 & 1 & 21.43 & 21.27 & 21.35 & 21.01 & point-like & \\
\hline 020218399 & $02^{\mathrm{h}} 27^{\mathrm{m}} 31.34^{\mathrm{s}}$ & $-04^{\circ} 30^{\mathrm{m}} 50.26^{\mathrm{s}}$ & 2.2255 & 14 & 1 & 22.92 & 22.40 & 22.54 & 22.19 & point-like & FORS \\
\hline 020212038 & $02^{\mathrm{h}} 26^{\mathrm{m}} 08.40^{\mathrm{s}}$ & $-04^{\circ} 31^{\mathrm{m}} 43.15^{\mathrm{s}}$ & 2.2082 & 14 & 1 & 22.91 & 22.28 & 22.02 & 21.46 & extended & FORS \\
\hline 020234610 & $02^{\mathrm{h}} 26^{\mathrm{m}} 58.99^{\mathrm{s}}$ & $-04^{\circ} 29^{\mathrm{m}} 06.02^{\mathrm{s}}$ & 2.1645 & 13 & 1 & 26.05 & 25.11 & 24.74 & 23.87 & $\ldots$ & $\ldots$ \\
\hline 020188089 & $02^{\mathrm{h}} 25^{\mathrm{m}} 25.68^{\mathrm{s}}$ & $-04^{\circ} 35^{\mathrm{m}} 09.45^{\mathrm{s}}$ & 2.1384 & 14 & 1 & 21.13 & 20.96 & 20.96 & 20.66 & point-like & $\ldots$ \\
\hline 020342478 & $02^{\mathrm{h}} 27^{\mathrm{m}} 24.52^{\mathrm{s}}$ & $-04^{\circ} 14^{\mathrm{m}} 40.01^{\mathrm{s}}$ & 2.0464 & 14 & 1 & 24.99 & 24.85 & 24.53 & 23.90 & $\ldots$ & $\ldots$ \\
\hline 020286836 & $02^{\mathrm{h}} 26^{\mathrm{m}} 22.17^{\mathrm{s}}$ & $-04^{\circ} 22^{\mathrm{m}} 21.62^{\mathrm{s}}$ & 2.0060 & 14 & 1 & 19.29 & 19.12 & 19.06 & 18.51 & point-like & $\ldots$ \\
\hline 020291309 & $02^{\mathrm{h}} 26^{\mathrm{m}} 31.23^{\mathrm{s}}$ & $-04^{\circ} 21^{\mathrm{m}} 28.87^{\mathrm{s}}$ & 1.9930 & 14 & 1 & 23.96 & 23.57 & 23.82 & 22.89 & & $\ldots$ \\
\hline 020159510 & $02^{\mathrm{h}} 27^{\mathrm{m}} 09.85^{\mathrm{s}}$ & $-04^{\circ} 39^{\mathrm{m}} 02.21^{\mathrm{s}}$ & 1.9309 & 14 & 1 & 22.73 & 22.41 & 22.45 & 21.98 & point-like & $\ldots$ \\
\hline 020461459 & $02^{\mathrm{h}} 27^{\mathrm{m}} 04.25^{\mathrm{s}}$ & $-04^{\circ} 23^{\mathrm{m}} 37.77^{\mathrm{s}}$ & 1.8211 & 13 & 1 & 23.50 & 22.93 & 22.42 & 21.60 & point-like & $\ldots$ \\
\hline 020278210 & $02^{\mathrm{h}} 27^{\mathrm{m}} 40.00^{\mathrm{s}}$ & $-04^{\circ} 23^{\mathrm{m}} 17.43^{\mathrm{s}}$ & 1.7574 & 13 & 1 & 22.69 & 21.88 & 22.29 & 21.37 & point-like & $\ldots$ \\
\hline 020254511 & $02^{\mathrm{h}} 27^{\mathrm{m}} 36.93^{\mathrm{s}}$ & $-04^{\circ} 26^{\mathrm{m}} 31.30^{\mathrm{s}}$ & 1.7466 & 14 & 1 & 20.77 & 20.85 & 20.86 & 20.66 & point-like & $\ldots$ \\
\hline 020177875 & $02^{\mathrm{h}} 26^{\mathrm{m}} 53.87^{\mathrm{s}}$ & $-04^{\circ} 36^{\mathrm{m}} 27.21^{\mathrm{s}}$ & 1.6821 & 13 & 1 & 24.02 & 23.66 & 23.37 & 22.54 & $\ldots$ & $\ldots$ \\
\hline 020232397 & $02^{\mathrm{h}} 26^{\mathrm{m}} 26.04^{\mathrm{s}}$ & $-04^{\circ} 29^{\mathrm{m}} 27.88^{\mathrm{s}}$ & 1.6280 & 14 & 1 & 23.72 & 23.32 & 23.15 & 22.69 & $\ldots$ & FORS \\
\hline 020114448 & $02^{\mathrm{h}} 27^{\mathrm{m}} 00.99^{\mathrm{s}}$ & $-04^{\circ} 45^{\mathrm{m}} 16.83^{\mathrm{s}}$ & 1.6140 & 13 & 1 & 23.40 & 23.36 & 22.98 & 22.24 & point-like & $\ldots$ \\
\hline 020120394 & $02^{\mathrm{h}} 26^{\mathrm{m}} 59.92^{\mathrm{s}}$ & $-04^{\circ} 44^{\mathrm{m}} 30.32^{\mathrm{s}}$ & 1.6120 & 14 & 1 & 21.27 & 20.97 & 20.78 & 20.38 & point-like & \\
\hline 020466135 & $02^{\mathrm{h}} 26^{\mathrm{m}} 46.99^{\mathrm{s}}$ & $-04^{\circ} 18^{\mathrm{m}} 37.56^{\mathrm{s}}$ & 1.5806 & 14 & 1 & 21.30 & 21.57 & 21.06 & 21.14 & point-like & VIMOS \\
\hline 020147295 & $02^{\mathrm{h}} 25^{\mathrm{m}} 29.19^{\mathrm{s}}$ & $-04^{\circ} 40^{\mathrm{m}} 44.16^{\mathrm{s}}$ & 1.5562 & 14 & 1 & 23.87 & 23.44 & 22.85 & 22.59 & $\ldots$ & FORS \\
\hline 020210524 & $02^{\mathrm{h}} 27^{\mathrm{m}} 07.55^{\mathrm{s}}$ & $-04^{\circ} 32^{\mathrm{m}} 02.98^{\mathrm{s}}$ & 1.5150 & 14 & 1 & 21.03 & 20.90 & 20.64 & 20.41 & point-like & FORS \\
\hline 020176565 & $02^{\mathrm{h}} 25^{\mathrm{m}} 28.06^{\mathrm{s}}$ & $-04^{\circ} 36^{\mathrm{m}} 41.59^{\mathrm{s}}$ & 1.5039 & 14 & 1 & 23.63 & 23.62 & 23.27 & 23.24 & & FORS \\
\hline 020223153 & $02^{\mathrm{h}} 26^{\mathrm{m}} 17.52^{\mathrm{s}}$ & $-04^{\circ} 30^{\mathrm{m}} 29.27^{\mathrm{s}}$ & 1.4777 & 214 & 1 & 21.19 & 21.05 & 20.94 & 20.66 & point-like & FORS \\
\hline 020367106 & $02^{\mathrm{h}} 26^{\mathrm{m}} 34.71^{\mathrm{s}}$ & $-04^{\circ} 11^{\mathrm{m}} 33.98^{\mathrm{s}}$ & 1.3973 & 14 & 1 & 23.27 & 23.02 & 22.55 & 22.42 & extended & FORS \\
\hline 020463196 & $02^{\mathrm{h}} 27^{\mathrm{m}} 00.65^{\mathrm{s}}$ & $-04^{\circ} 21^{\mathrm{m}} 49.00^{\mathrm{s}}$ & 1.3875 & 14 & 1 & 24.50 & 24.43 & 23.92 & 23.28 & $\ldots$ & $\ldots$ \\
\hline 020179225 & $02^{\mathrm{h}} 27^{\mathrm{m}} 02.15^{\mathrm{s}}$ & $-04^{\circ} 36^{\mathrm{m}} 15.96^{\mathrm{s}}$ & 1.3860 & 13 & 1 & 23.91 & 23.51 & 23.02 & 22.39 & point-like & \\
\hline 020467628 & $02^{\mathrm{h}} 27^{\mathrm{m}} 04.06^{\mathrm{s}}$ & $-04^{\circ} 17^{\mathrm{m}} 09.77^{\mathrm{s}}$ & 1.3582 & 13 & 1 & 21.98 & 21.82 & 21.62 & 21.36 & point-like & $\ldots$ \\
\hline
\end{tabular}


Table B.1. continued.

\begin{tabular}{|c|c|c|c|c|c|c|c|c|c|c|c|}
\hline $\begin{array}{c}\text { Object ID } \\
(1)\end{array}$ & $\begin{array}{c}\alpha_{J 2000} \\
(2)\end{array}$ & $\begin{array}{c}\delta_{J 2000} \\
(3)\end{array}$ & $\begin{array}{c}z \\
(4)\end{array}$ & $\begin{array}{r}\text { Flag } \\
(5)\end{array}$ & $\begin{array}{c}\text { Epoch } \\
\text { (6) }\end{array}$ & $\begin{array}{c}B_{\mathrm{AB}} \\
(7)\end{array}$ & $\begin{array}{l}V_{\mathrm{AB}} \\
(8)\end{array}$ & $\begin{array}{c}R_{\mathrm{AB}} \\
(9)\end{array}$ & $\begin{array}{l}I_{\mathrm{AB}} \\
(10)\end{array}$ & $\begin{array}{c}\text { Morphology } \\
\text { (11) }\end{array}$ & $\begin{array}{c}\text { Remark } \\
\text { (12) }\end{array}$ \\
\hline 020258622 & $02^{\mathrm{h}} 26^{\mathrm{m}} 20.06^{\mathrm{s}}$ & $-04^{\circ} 25^{\mathrm{m}} 54.51^{\mathrm{s}}$ & 1.3386 & 14 & 1 & 24.45 & 23.85 & 23.47 & 22.74 & & \\
\hline 020165108 & $02^{\mathrm{h}} 26^{\mathrm{m}} 59.85^{\mathrm{s}}$ & $-04^{\circ} 38^{\mathrm{m}} 12.68^{\mathrm{s}}$ & 1.3219 & 13 & 1 & 24.71 & 24.05 & 23.79 & 23.09 & . & \\
\hline 020163018 & $02^{\mathrm{h}} 26^{\mathrm{m}} 45.20^{\mathrm{s}}$ & $-04^{\circ} 38^{\mathrm{m}} 30.58^{\mathrm{s}}$ & 1.3208 & 14 & 1 & 23.89 & 23.62 & 23.30 & 23.12 & & FORS \\
\hline 020118483 & $02^{\mathrm{h}} 27^{\mathrm{m}} 36.06^{\mathrm{s}}$ & $-04^{\circ} 44^{\mathrm{m}} 41.89^{\mathrm{s}}$ & 1.2606 & 13 & 1 & 23.81 & 23.44 & 23.29 & 22.86 & $\ldots$ & $\ldots$ \\
\hline 020213000 & $02^{\mathrm{h}} 26^{\mathrm{m}} 47.88^{\mathrm{s}}$ & $-04^{\circ} 31^{\mathrm{m}} 35.20^{\mathrm{s}}$ & 1.2250 & 13 & 1 & 22.30 & 22.02 & 21.76 & 21.44 & point-like & $\ldots$ \\
\hline 020237445 & $02^{\mathrm{h}} 25^{\mathrm{m}} 57.38^{\mathrm{s}}$ & $-04^{\circ} 28^{\mathrm{m}} 46.04^{\mathrm{s}}$ & 1.2138 & 14 & 1 & 23.93 & 23.54 & 23.06 & 22.43 & extended & $\ldots$ \\
\hline 020364478 & $02^{\mathrm{h}} 26^{\mathrm{m}} 49.41^{\mathrm{s}}$ & $-04^{\circ} 11^{\mathrm{m}} 53.30^{\mathrm{s}}$ & 1.1573 & 14 & 1 & 22.94 & 22.74 & 22.25 & 21.74 & extended & \\
\hline 020243922 & $02^{\mathrm{h}} 27^{\mathrm{m}} 47.33^{\mathrm{s}}$ & $-04^{\circ} 27^{\mathrm{m}} 53.20^{\mathrm{s}}$ & 1.1203 & 14 & 1 & 22.03 & 21.72 & 21.60 & 21.29 & point-like & $\ldots$ \\
\hline 020329650 & $02^{\mathrm{h}} 26^{\mathrm{m}} 08.71^{\mathrm{s}}$ & $-04^{\circ} 16^{\mathrm{m}} 34.53^{\mathrm{s}}$ & 1.0498 & 14 & 1 & 21.53 & 21.15 & 20.97 & 20.85 & point-like & $\ldots$ \\
\hline 020158952 & $02^{\mathrm{h}} 26^{\mathrm{m}} 17.81^{\mathrm{s}}$ & $-04^{\circ} 39^{\mathrm{m}} 08.50^{\mathrm{s}}$ & 0.8738 & 14 & 1 & 22.82 & 22.16 & 22.00 & 21.41 & extended & $\ldots$ \\
\hline 020351277 & $02^{\mathrm{h}} 25^{\mathrm{m}} 57.41^{\mathrm{s}}$ & $-04^{\circ} 13^{\mathrm{m}} 39.43^{\mathrm{s}}$ & 0.6061 & 14 & 1 & 20.61 & 20.40 & 20.32 & 19.84 & extended & \\
\hline 020190479 & $02^{\mathrm{h}} 25^{\mathrm{m}} 45.55^{\mathrm{s}}$ & $-04^{\circ} 34^{\mathrm{m}} 45.18^{\mathrm{s}}$ & 0.1524 & 14 & 1 & 21.99 & 21.56 & 21.65 & 21.33 & point-like & \\
\hline $1003+01$ & Wide mode & $34 \mathrm{AGN}$ & & & & & & & & & \\
\hline 100561715 & $10^{\mathrm{h}} 04^{\mathrm{m}} 26.84^{\mathrm{s}}$ & $+02^{\circ} 24^{\mathrm{m}} 44.82^{\mathrm{s}}$ & 4.3600 & 14 & 2 & $\ldots$ & 23.47 & 22.67 & 21.89 & point-like & \\
\hline 100359356 & $10^{\mathrm{h}} 03^{\mathrm{m}} 38.72^{\mathrm{s}}$ & $+01^{\circ} 56^{\mathrm{m}} 41.61^{\mathrm{s}}$ & 3.6805 & 14 & 2 & 22.93 & 21.39 & 21.45 & 20.75 & point-like & $\ldots$ \\
\hline 100105943 & $10^{\mathrm{h}} 03^{\mathrm{m}} 46.33^{\mathrm{s}}$ & $+01^{\circ} 19^{\mathrm{m}} 11.04^{\mathrm{s}}$ & 3.5553 & 13 & 1 & $\ldots$ & $\ldots$ & $\ldots$ & 21.15 & point-like & \\
\hline 100471137 & $10^{\mathrm{h}} 02^{\mathrm{m}} 56.58^{\mathrm{s}}$ & $+02^{\circ} 11^{\mathrm{m}} 58.78^{\mathrm{s}}$ & 3.4938 & 14 & 2 & 21.51 & 20.46 & 20.46 & 20.08 & point-like & $\ldots$ \\
\hline 100049642 & $10^{\mathrm{h}} 03^{\mathrm{m}} 42.42^{\mathrm{s}}$ & $+01^{\circ} 07^{\mathrm{m}} 55.37^{\mathrm{s}}$ & 3.1918 & 13 & 2 & $\ldots$ & $\ldots$ & $\ldots$ & 20.51 & point-like & $\ldots$ \\
\hline 100245809 & $10^{\mathrm{h}} 04^{\mathrm{m}} 00.36^{\mathrm{s}}$ & $+01^{\circ} 40^{\mathrm{m}} 45.74^{\mathrm{s}}$ & 3.0789 & 14 & 1 & 22.71 & 22.01 & 21.94 & 21.62 & point-like & $\ldots$ \\
\hline 100049420 & $10^{\mathrm{h}} 07^{\mathrm{m}} 13.20^{\mathrm{s}}$ & $+01^{\circ} 07^{\mathrm{m}} 53.62^{\mathrm{s}}$ & 2.9450 & 14 & 2 & $\ldots$ & $\ldots$ & $\ldots$ & 21.57 & point-like & \\
\hline 100168207 & $10^{\mathrm{h}} 04^{\mathrm{m}} 36.55^{\mathrm{s}}$ & $+01^{\circ} 30^{\mathrm{m}} 05.86^{\mathrm{s}}$ & 2.7152 & 14 & 1 & 22.38 & 21.84 & 22.14 & 22.40 & point-like & $\ldots$ \\
\hline 100343840 & $10^{\mathrm{h}} 04^{\mathrm{m}} 32.08^{\mathrm{s}}$ & $+01^{\circ} 54^{\mathrm{m}} 24.12^{\mathrm{s}}$ & 2.3666 & 14 & 1 & 20.68 & 20.40 & 20.15 & 19.76 & point-like & FORS \\
\hline 100126868 & $10^{\mathrm{h}} 03^{\mathrm{m}} 08.80^{\mathrm{s}}$ & $+01^{\circ} 23^{\mathrm{m}} 16.56^{\mathrm{s}}$ & 2.3302 & 14 & 1 & $\ldots$ & $\ldots$ & $\ldots$ & 20.34 & point-like & $\ldots$ \\
\hline 100578140 & $10^{\mathrm{h}} 04^{\mathrm{m}} 29.89^{\mathrm{s}}$ & $+02^{\circ} 28^{\mathrm{m}} 21.44^{\mathrm{s}}$ & 2.2884 & 13 & 2 & 22.13 & 22.08 & 22.50 & 21.71 & point-like & $\ldots$ \\
\hline 100566130 & $10^{\mathrm{h}} 04^{\mathrm{m}} 15.12^{\mathrm{s}}$ & $+02^{\circ} 25^{\mathrm{m}} 42.17^{\mathrm{s}}$ & 2.2030 & 14 & 2 & 22.73 & 22.37 & 22.48 & 21.69 & point-like & $\ldots$ \\
\hline 100123590 & $10^{\mathrm{h}} 04^{\mathrm{m}} 46.72^{\mathrm{s}}$ & $+01^{\circ} 22^{\mathrm{m}} 39.10^{\mathrm{s}}$ & 2.0963 & 13 & 1 & $\ldots$ & $\ldots$ & $\ldots$ & 21.47 & point-like & $\ldots$ \\
\hline 100530812 & $10^{\mathrm{h}} 04^{\mathrm{m}} 48.64^{\mathrm{s}}$ & $+02^{\circ} 19^{\mathrm{m}} 44.38^{\mathrm{s}}$ & 2.0201 & 14 & 2 & 21.00 & 20.53 & 20.75 & 20.39 & point-like & $\ldots$ \\
\hline 100447217 & $10^{\mathrm{h}} 03^{\mathrm{m}} 12.70^{\mathrm{s}}$ & $+02^{\circ} 08^{\mathrm{m}} 50.66^{\mathrm{s}}$ & 1.8900 & 13 & 2 & 22.71 & 22.50 & 22.51 & 21.91 & point-like & $\ldots$ \\
\hline 100122852 & $10^{\mathrm{h}} 02^{\mathrm{m}} 11.17^{\mathrm{s}}$ & $+01^{\circ} 22^{\mathrm{m}} 28.58^{\mathrm{s}}$ & 1.8007 & 14 & 1 & $\ldots$ & $\ldots$ & $\ldots$ & 19.86 & point-like & 2QZ \\
\hline 100507363 & $10^{\mathrm{h}} 04^{\mathrm{m}} 50.02^{\mathrm{s}}$ & $+02^{\circ} 16^{\mathrm{m}} 42.21^{\mathrm{s}}$ & 1.7842 & 14 & 2 & 22.71 & 22.47 & 22.18 & 21.64 & extended & $\ldots$ \\
\hline 100451895 & $10^{\mathrm{h}} 04^{\mathrm{m}} 38.01^{\mathrm{s}}$ & $+02^{\circ} 09^{\mathrm{m}} 25.07^{\mathrm{s}}$ & 1.7806 & 13 & 1 & 20.46 & 20.31 & 20.36 & 20.03 & point-like & $\ldots$ \\
\hline 100232259 & $10^{\mathrm{h}} 03^{\mathrm{m}} 30.37^{\mathrm{s}}$ & $+01^{\circ} 38^{\mathrm{m}} 51.18^{\mathrm{s}}$ & 1.7647 & 14 & 1 & 21.37 & 21.30 & 21.33 & 21.09 & point-like & FORS \\
\hline 100290682 & $10^{\mathrm{h}} 03^{\mathrm{m}} 11.33^{\mathrm{s}}$ & $+01^{\circ} 47^{\mathrm{m}} 01.56^{\mathrm{s}}$ & 1.5487 & 14 & 1 & $\ldots$ & $\ldots$ & $\ldots$ & 21.45 & extended & FORS \\
\hline 100046262 & $10^{\mathrm{h}} 07^{\mathrm{m}} 34.87^{\mathrm{s}}$ & $+01^{\circ} 07^{\mathrm{m}} 13.95^{\mathrm{s}}$ & 1.4627 & 14 & 2 & $\ldots$ & $\ldots$ & $\ldots$ & 20.89 & point-like & SDSS \\
\hline 100198426 & $10^{\mathrm{h}} 03^{\mathrm{m}} 42.73^{\mathrm{s}}$ & $+01^{\circ} 34^{\mathrm{m}} 12.51^{\mathrm{s}}$ & 1.3372 & 14 & 1 & 23.32 & 22.96 & 22.82 & 22.09 & point-like & $\ldots$ \\
\hline 100139500 & $10^{\mathrm{h}} 02^{\mathrm{m}} 57.37^{\mathrm{s}}$ & $+01^{\circ} 25^{\mathrm{m}} 40.38^{\mathrm{s}}$ & 1.2478 & 13 & 1 & $\ldots$ & $\ldots$ & $\ldots$ & 20.96 & point-like & $\ldots$ \\
\hline 100327652 & $10^{\mathrm{h}} 03^{\mathrm{m}} 13.81^{\mathrm{s}}$ & $+01^{\circ} 52^{\mathrm{m}} 13.97^{\mathrm{s}}$ & 1.2173 & 14 & 1 & 23.85 & 23.43 & 22.90 & 22.39 & extended & FORS \\
\hline 100048462 & $10^{\mathrm{h}} 03^{\mathrm{m}} 13.77^{\mathrm{s}}$ & $+01^{\circ} 07^{\mathrm{m}} 41.06^{\mathrm{s}}$ & 1.2028 & 13 & 2 & $\ldots$ & $\ldots$ & $\ldots$ & 20.43 & point-like & $\ldots$ \\
\hline 100184041 & $10^{\mathrm{h}} 03^{\mathrm{m}} 49.53^{\mathrm{s}}$ & $+01^{\circ} 32^{\mathrm{m}} 12.26^{\mathrm{s}}$ & 1.2028 & 14 & 1 & 23.44 & 22.94 & 22.88 & 21.87 & point-like & $\ldots$ \\
\hline 100210521 & $10^{\mathrm{h}} 03^{\mathrm{m}} 27.33^{\mathrm{s}}$ & $+01^{\circ} 35^{\mathrm{m}} 50.91^{\mathrm{s}}$ & 1.1723 & 14 & 1 & 22.05 & 21.73 & 21.56 & 21.58 & point-like & $\ldots$ \\
\hline 100338914 & $10^{\mathrm{h}} 04^{\mathrm{m}} 13.45^{\mathrm{s}}$ & $+01^{\circ} 53^{\mathrm{m}} 41.38^{\mathrm{s}}$ & 1.1584 & 14 & 1 & 20.15 & 19.80 & 19.78 & 19.73 & extended & $\ldots$ \\
\hline 100241696 & $10^{\mathrm{h}} 04^{\mathrm{m}} 11.84^{\mathrm{s}}$ & $+01^{\circ} 40^{\mathrm{m}} 06.47^{\mathrm{s}}$ & 1.1112 & 13 & 1 & 22.59 & 21.89 & 22.19 & 21.95 & point-like & $\ldots$ \\
\hline 100190464 & $10^{\mathrm{h}} 04^{\mathrm{m}} 25.14^{\mathrm{s}}$ & $+01^{\circ} 33^{\mathrm{m}} 07.74^{\mathrm{s}}$ & 1.0760 & 14 & 1 & 22.98 & 22.38 & 22.41 & 21.66 & extended & $\ldots$ \\
\hline 100641029 & $10^{\mathrm{h}} 04^{\mathrm{m}} 00.44^{\mathrm{s}}$ & $+02^{\circ} 41^{\mathrm{m}} 22.83^{\mathrm{s}}$ & 0.8322 & 14 & 2 & 22.18 & 21.52 & 21.70 & 21.08 & extended & $\ldots$ \\
\hline $1400+05$ & Wide mode & 28 AGN & & & & & & & & & \\
\hline 140431249 & $13^{\mathrm{h}} 55^{\mathrm{m}} 47.47^{\mathrm{s}}$ & $+05^{\circ} 11^{\mathrm{m}} 21.63^{\mathrm{s}}$ & 3.8452 & 14 & 2 & & $\ldots$ & & 21.42 & $\ldots$ & $\ldots$ \\
\hline 140465826 & $13^{\mathrm{h}} 58^{\mathrm{m}} 37.30^{\mathrm{s}}$ & $+05^{\circ} 17^{\mathrm{m}} 14.44^{\mathrm{s}}$ & 3.2900 & 14 & 2 & 20.92 & 19.92 & 19.89 & 20.11 & $\ldots$ & $\ldots$ \\
\hline 140191403 & $13^{\mathrm{h}} 57^{\mathrm{m}} 44.60^{\mathrm{s}}$ & $+04^{\circ} 34^{\mathrm{m}} 42.28^{\mathrm{s}}$ & 3.1704 & 14 & 2 & $\ldots$ & $\ldots$ & 21.60 & 22.10 & $\ldots$ & $\ldots$ \\
\hline 140156421 & $13^{\mathrm{h}} 57^{\mathrm{m}} 54.50^{\mathrm{s}}$ & $+04^{\circ} 29^{\mathrm{m}} 28.69^{\mathrm{s}}$ & 3.1464 & 14 & 2 & 22.76 & 21.78 & 21.80 & 21.74 & $\ldots$ & $\ldots$ \\
\hline 140493205 & $13^{\mathrm{h}} 57^{\mathrm{m}} 36.79^{\mathrm{s}}$ & $+05^{\circ} 21^{\mathrm{m}} 53.11^{\mathrm{s}}$ & 2.8650 & 14 & 2 & $\ldots$ & 21.82 & 21.69 & 21.61 & $\ldots$ & $\ldots$ \\
\hline 140040016 & $13^{\mathrm{h}} 58^{\mathrm{m}} 30.18^{\mathrm{s}}$ & $+04^{\circ} 10^{\mathrm{m}} 08.54^{\mathrm{s}}$ & 2.8379 & 13 & 2 & 21.29 & 21.44 & 21.45 & 21.49 & $\ldots$ & $\ldots$ \\
\hline 140432542 & $13^{\mathrm{h}} 55^{\mathrm{m}} 41.68^{\mathrm{s}}$ & $+05^{\circ} 11^{\mathrm{m}} 36.10^{\mathrm{s}}$ & 2.8000 & 14 & 2 & $\ldots$ & $\ldots$ & $\ldots$ & 21.80 & & $\ldots$ \\
\hline 140523286 & $13^{\mathrm{h}} 58^{\mathrm{m}} 30.57^{\mathrm{s}}$ & $+05^{\circ} 27^{\mathrm{m}} 02.35^{\mathrm{s}}$ & 2.7100 & 13 & 2 & 20.50 & 20.24 & 19.95 & 19.92 & $\cdots$ & $\ldots$ \\
\hline 140373668 & $13^{\mathrm{h}} 55^{\mathrm{m}} 52.45^{\mathrm{s}}$ & $+05^{\circ} 01^{\mathrm{m}} 24.81^{\mathrm{s}}$ & 2.3130 & 14 & 2 & $\ldots$ & $\ldots$ & $\cdots$ & 20.98 & $\cdots$ & $\ldots$ \\
\hline 140338871 & $13^{\mathrm{h}} 55^{\mathrm{m}} 40.98^{\mathrm{s}}$ & $+04^{\circ} 56^{\mathrm{m}} 17.57^{\mathrm{s}}$ & 2.1084 & 14 & 2 & $\ldots$ & $\ldots$ & $\ldots$ & 22.23 & $\ldots$ & $\ldots$ \\
\hline 140166360 & $13^{\mathrm{h}} 55^{\mathrm{m}} 55.44^{\mathrm{s}}$ & $+04^{\circ} 31^{\mathrm{m}} 07.70^{\mathrm{s}}$ & 2.1000 & 14 & 2 & $\ldots$ & $\cdots$ & $\ldots$ & 21.30 & $\ldots$ & $\ldots$ \\
\hline 140166951 & $13^{\mathrm{h}} 55^{\mathrm{m}} 54.92^{\mathrm{s}}$ & $+04^{\circ} 31^{\mathrm{m}} 14.32^{\mathrm{s}}$ & 1.9912 & 14 & 2 & $\ldots$ & $\ldots$ & $\ldots$ & 21.79 & $\ldots$ & $\ldots$ \\
\hline
\end{tabular}


Table B.1. continued.

\begin{tabular}{|c|c|c|c|c|c|c|c|c|c|c|c|}
\hline $\begin{array}{l}\text { Object ID } \\
\text { (1) }\end{array}$ & $\begin{array}{c}\alpha_{J 2000} \\
(2)\end{array}$ & $\begin{array}{c}\delta_{J 2000} \\
(3)\end{array}$ & $\begin{array}{c}z \\
(4)\end{array}$ & $\begin{array}{r}\text { Flag } \\
(5)\end{array}$ & $\begin{array}{l}\text { Epoch } \\
\text { (6) }\end{array}$ & $\begin{array}{l}B_{\mathrm{AB}} \\
\text { (7) }\end{array}$ & $\begin{array}{l}V_{\mathrm{AB}} \\
(8)\end{array}$ & $\begin{array}{l}R_{\mathrm{AB}} \\
(9)\end{array}$ & $\begin{array}{l}I_{\mathrm{AB}} \\
(10)\end{array}$ & $\begin{array}{l}\text { Morphology } \\
\text { (11) }\end{array}$ & $\begin{array}{l}\text { Remark } \\
\text { (12) }\end{array}$ \\
\hline 140265284 & $13^{\mathrm{h}} 55^{\mathrm{m}} 42.76^{\mathrm{s}}$ & $+04^{\circ} 45^{\mathrm{m}} 46.62^{\mathrm{s}}$ & 1.8549 & 13 & 2 & $\ldots$ & 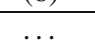 & (2) & 21.41 & (in) & $\ldots$ \\
\hline 140520998 & $13^{\mathrm{h}} 57^{\mathrm{m}} 53.93^{\mathrm{s}}$ & $+05^{\circ} 26^{\mathrm{m}} 39.07^{\mathrm{s}}$ & 1.8293 & 13 & 2 & $\ldots$ & 21.09 & 21.10 & 20.84 & $\ldots$ & $\ldots$ \\
\hline 140363408 & $13^{\mathrm{h}} 58^{\mathrm{m}} 36.16^{\mathrm{s}}$ & $+04^{\circ} 59^{\mathrm{m}} 49.74^{\mathrm{s}}$ & 1.8260 & 13 & 2 & 22.12 & 21.86 & 21.72 & 21.81 & $\ldots$ & $\ldots$ \\
\hline 140495178 & $13^{\mathrm{h}} 59^{\mathrm{m}} 33.29^{\mathrm{s}}$ & $+05^{\circ} 22^{\mathrm{m}} 09.08^{\mathrm{s}}$ & 1.8241 & 13 & 2 & 21.77 & 21.05 & 20.71 & 20.75 & & $\ldots$ \\
\hline 140433507 & $14^{\mathrm{h}} 00^{\mathrm{m}} 33.04^{\mathrm{s}}$ & $+05^{\circ} 11^{\mathrm{m}} 48.09^{\mathrm{s}}$ & 1.7645 & 13 & 2 & 21.20 & 21.14 & 21.56 & 21.09 & $\ldots$ & $\ldots$ \\
\hline 140338689 & $14^{\mathrm{h}} 01^{\mathrm{m}} 34.46^{\mathrm{s}}$ & $+04^{\circ} 56^{\mathrm{m}} 17.27^{\mathrm{s}}$ & 1.4420 & 14 & 2 & 22.01 & 21.44 & 21.03 & 20.69 & $\ldots$ & $\cdots$ \\
\hline 140441955 & $13^{\mathrm{h}} 58^{\mathrm{m}} 28.26^{\mathrm{s}}$ & $+05^{\circ} 13^{\mathrm{m}} 11.92^{\mathrm{s}}$ & 1.4290 & 13 & 2 & 23.15 & 21.94 & 21.47 & 22.01 & $\ldots$ & $\ldots$ \\
\hline 140305471 & $13^{\mathrm{h}} 58^{\mathrm{m}} 16.55^{\mathrm{s}}$ & $+04^{\circ} 51^{\mathrm{m}} 35.36^{\mathrm{s}}$ & 1.3703 & 13 & 2 & 21.04 & 21.05 & 21.47 & 21.02 & $\ldots$ & $\ldots$ \\
\hline 140222324 & $13^{\mathrm{h}} 57^{\mathrm{m}} 56.92^{\mathrm{s}}$ & $+04^{\circ} 39^{\mathrm{m}} 20.01^{\mathrm{s}}$ & 1.3053 & 14 & 2 & $\ldots$ & 22.01 & 21.88 & 21.66 & $\ldots$ & $\ldots$ \\
\hline 140433055 & $13^{\mathrm{h}} 56^{\mathrm{m}} 49.40^{\mathrm{s}}$ & $+05^{\circ} 11^{\mathrm{m}} 43.77^{\mathrm{s}}$ & 1.2077 & 13 & 2 & $\ldots$ & $\ldots$ & 21.91 & 22.28 & $\ldots$ & $\ldots$ \\
\hline 140306523 & $13^{\mathrm{h}} 56^{\mathrm{m}} 49.91^{\mathrm{s}}$ & $+04^{\circ} 51^{\mathrm{m}} 37.87^{\mathrm{s}}$ & 1.1902 & 13 & 2 & & $\ldots$ & 19.72 & 20.06 & $\ldots$ & $\ldots$ \\
\hline 140192158 & $13^{\mathrm{h}} 58^{\mathrm{m}} 35.43^{\mathrm{s}}$ & $+04^{\circ} 34^{\mathrm{m}} 49.21^{\mathrm{s}}$ & 1.1265 & 13 & 2 & 22.79 & 22.34 & 21.97 & 22.06 & $\ldots$ & $\ldots$ \\
\hline 140443623 & $13^{\mathrm{h}} 58^{\mathrm{m}} 13.27^{\mathrm{s}}$ & $+05^{\circ} 13^{\mathrm{m}} 28.45^{\mathrm{s}}$ & 1.1195 & 14 & 2 & 22.44 & 21.98 & 22.05 & 21.43 & $\ldots$ & $\ldots$ \\
\hline 140278593 & $13^{\mathrm{h}} 59^{\mathrm{m}} 44.60^{\mathrm{s}}$ & $+04^{\circ} 47^{\mathrm{m}} 40.37^{\mathrm{s}}$ & 1.0460 & 13 & 2 & 20.68 & 20.18 & 20.68 & 20.45 & $\ldots$ & $\ldots$ \\
\hline 140215102 & $13^{\mathrm{h}} 56^{\mathrm{m}} 39.41^{\mathrm{s}}$ & $+04^{\circ} 38^{\mathrm{m}} 14.32^{\mathrm{s}}$ & 0.5487 & 14 & 2 & & $\ldots$ & 21.14 & 20.94 & $\cdots$ & $\ldots$ \\
\hline 140360727 & $13^{\mathrm{h}} 55^{\mathrm{m}} 44.37^{\mathrm{s}}$ & $+04^{\circ} 59^{\mathrm{m}} 15.10^{\mathrm{s}}$ & 0.1236 & 14 & 2 & $\ldots$ & $\ldots$ & $\ldots$ & 18.58 & $\ldots$ & $\ldots$ \\
\hline $2217+00$ & Wide mode & $105 \mathrm{AGN}$ & & & & & & & & & \\
\hline 220567224 & $22^{\mathrm{h}} 16^{\mathrm{m}} 44.02^{\mathrm{s}}$ & $+00^{\circ} 13^{\mathrm{m}} 48.54^{\mathrm{s}}$ & 5.0042 & 14 & 1 & & 22.90 & 21.66 & 20.07 & point-like & $\ldots$ \\
\hline 220437943 & $22^{\mathrm{h}} 20^{\mathrm{m}} 50.80^{\mathrm{s}}$ & $+00^{\circ} 19^{\mathrm{m}} 59.53^{\mathrm{s}}$ & 4.6694 & 14 & 2 & $\cdots$ & 21.83 & 20.60 & 20.10 & point-like & $\begin{array}{l}\cdots \\
\cdots\end{array}$ \\
\hline 220490264 & $22^{\mathrm{h}} 17^{\mathrm{m}} 05.70^{\mathrm{s}}$ & $-00^{\circ} 13^{\mathrm{m}} 07.28^{\mathrm{s}}$ & 4.6677 & 14 & 2 & & 21.94 & 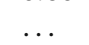 & 20.42 & point-like & $\ldots$ \\
\hline 220183694 & $22^{\mathrm{h}} 20^{\mathrm{m}} 32.47^{\mathrm{s}}$ & $+00^{\circ} 25^{\mathrm{m}} 38.16^{\mathrm{s}}$ & 4.1928 & 14 & 2 & 23.69 & 21.33 & 20.11 & 20.14 & point-like & $\ldots$ \\
\hline 220267678 & $22^{\mathrm{h}} 21^{\mathrm{m}} 32.55^{\mathrm{s}}$ & $+01^{\circ} 00^{\mathrm{m}} 05.84^{\mathrm{s}}$ & 3.8331 & 14 & 2 & $\ldots$ & $\ldots$ & $\ldots$ & 21.34 & point-like & $\ldots$ \\
\hline 220270600 & $22^{\mathrm{h}} 21^{\mathrm{m}} 50.78^{\mathrm{s}}$ & $+01^{\circ} 01^{\mathrm{m}} 02.34^{\mathrm{s}}$ & 3.7351 & 14 & 2 & $\ldots$ & $\ldots$ & $\ldots$ & 22.34 & extended & $\ldots$ \\
\hline 220010371 & $22^{\mathrm{h}} 14^{\mathrm{m}} 28.40^{\mathrm{s}}$ & $+00^{\circ} 27^{\mathrm{m}} 32.40^{\mathrm{s}}$ & 3.6952 & 214 & 1 & $\cdots$ & $\cdots$ & $\cdots$ & 21.78 & point-like & $\cdots$ \\
\hline 220055529 & $22^{\mathrm{h}} 15^{\mathrm{m}} 54.10^{\mathrm{s}}$ & $+00^{\circ} 40^{\mathrm{m}} 55.47^{\mathrm{s}}$ & 3.5941 & 13 & 1 & $\begin{array}{l}\cdots \\
\cdots\end{array}$ & $\begin{array}{l}\cdots \\
\cdots\end{array}$ & $\begin{array}{l}\cdots \\
\cdots\end{array}$ & 21.42 & point-like & $\begin{array}{l}\cdots \\
\cdots\end{array}$ \\
\hline 220300661 & $22^{\mathrm{h}} 19^{\mathrm{m}} 32.96^{\mathrm{s}}$ & $+01^{\circ} 10^{\mathrm{m}} 46.87^{\mathrm{s}}$ & 3.5879 & 214 & 2 & $\ldots$ & $\ldots$ & $\ldots$ & 19.59 & extended & $\ldots$ \\
\hline 220576935 & $22^{\mathrm{h}} 17^{\mathrm{m}} 22.27^{\mathrm{s}}$ & $+00^{\circ} 16^{\mathrm{m}} 40.41^{\mathrm{s}}$ & 3.3650 & 14 & 2 & 22.10 & 20.86 & 20.92 & 20.79 & point-like & $\ldots$ \\
\hline 220359141 & $22^{\mathrm{h}} 19^{\mathrm{m}} 54.56^{\mathrm{s}}$ & $-00^{\circ} 15^{\mathrm{m}} 46.22^{\mathrm{s}}$ & 3.1582 & 214 & 2 & & $\ldots$ & & 22.64 & extended & $\ldots$ \\
\hline 220157547 & $22^{\mathrm{h}} 13^{\mathrm{m}} 51.40^{\mathrm{s}}$ & $+01^{\circ} 11^{\mathrm{m}} 11.53^{\mathrm{s}}$ & 3.1518 & 14 & 2 & & $\ldots$ & & 22.19 & extended & $\ldots$ \\
\hline 220133794 & $22^{\mathrm{h}} 18^{\mathrm{m}} 00.48^{\mathrm{s}}$ & $+01^{\circ} 04^{\mathrm{m}} 07.32^{\mathrm{s}}$ & 3.1473 & 14 & 2 & & $\ldots$ & $\ldots$ & 22.16 & point-like & $\ldots$ \\
\hline 220617869 & $22^{\mathrm{h}} 18^{\mathrm{m}} 52.17^{\mathrm{s}}$ & $+00^{\circ} 34^{\mathrm{m}} 50.72^{\mathrm{s}}$ & 3.1334 & 14 & 2 & 24.11 & 23.16 & 22.27 & 22.25 & point-like & $\ldots$ \\
\hline 220215380 & $22^{\mathrm{h}} 19^{\mathrm{m}} 43.32^{\mathrm{s}}$ & $+00^{\circ} 41^{\mathrm{m}} 19.18^{\mathrm{s}}$ & 3.1300 & 14 & 2 & 19.91 & 19.09 & 18.98 & 19.01 & point-like & $\ldots$ \\
\hline 220576817 & $22^{\mathrm{h}} 15^{\mathrm{m}} 09.17^{\mathrm{s}}$ & $+00^{\circ} 16^{\mathrm{m}} 42.38^{\mathrm{s}}$ & 3.0957 & 14 & 1 & - & $\ldots$ & $\ldots$ & 21.81 & point-like & $\ldots$ \\
\hline 220309346 & $22^{\mathrm{h}} 20^{\mathrm{m}} 43.12^{\mathrm{s}}$ & $+01^{\circ} 13^{\mathrm{m}} 51.19^{\mathrm{s}}$ & 3.0899 & 14 & 2 & & $\ldots$ & $\ldots$ & 22.11 & point-like & $\ldots$ \\
\hline 220391155 & $22^{\mathrm{h}} 18^{\mathrm{m}} 54.28^{\mathrm{s}}$ & $-00^{\circ} 00^{\mathrm{m}} 58.53^{\mathrm{s}}$ & 3.0870 & 14 & 2 & 21.78 & 21.03 & 20.98 & 20.89 & point-like & $\ldots$ \\
\hline 220205172 & $22^{\mathrm{h}} 19^{\mathrm{m}} 58.22^{\mathrm{s}}$ & $+00^{\circ} 37^{\mathrm{m}} 10.08^{\mathrm{s}}$ & 3.0759 & 14 & 2 & 19.94 & 19.30 & 19.06 & 19.06 & point-like & $\begin{array}{l}\cdots \\
\cdots\end{array}$ \\
\hline 220575888 & $22^{\mathrm{h}} 17^{\mathrm{m}} 36.55^{\mathrm{s}}$ & $+00^{\circ} 16^{\mathrm{m}} 23.09^{\mathrm{s}}$ & 3.0755 & 14 & 1 & 22.16 & 21.50 & 21.23 & 21.25 & point-like & $\begin{array}{l}\cdots \\
\cdots\end{array}$ \\
\hline 220133609 & $22^{\mathrm{h}} 16^{\mathrm{m}} 36.81^{\mathrm{s}}$ & $+01^{\circ} 04^{\mathrm{m}} 02.27^{\mathrm{s}}$ & 3.0507 & 14 & 2 & 2.10 & 21.00 & $\ldots$ & 20.31 & extended & $\begin{array}{l}\cdots \\
\cdots\end{array}$ \\
\hline 220580912 & $22^{\mathrm{h}} 15^{\mathrm{m}} 56.66^{\mathrm{s}}$ & $+00^{\circ} 17^{\mathrm{m}} 52.28^{\mathrm{s}}$ & 3.0432 & 13 & 1 & $\ldots$ & $\ldots$ & $\ldots$ & 22.10 & point-like & $\ldots$ \\
\hline 220410190 & $22^{\mathrm{h}} 18^{\mathrm{m}} 58.92^{\mathrm{s}}$ & $+00^{\circ} 07^{\mathrm{m}} 12.45^{\mathrm{s}}$ & 3.0335 & 14 & 2 & 23.15 & 22.48 & 22.03 & 21.70 & point-like & ... \\
\hline 220056847 & $22^{\mathrm{h}} 14^{\mathrm{m}} 48.77^{\mathrm{s}}$ & $+00^{\circ} 41^{\mathrm{m}} 16.67^{\mathrm{s}}$ & 3.0015 & 14 & 1 & $\ldots$ & $\ldots$ & $\ldots$ & 21.38 & point-like & $\cdots$ \\
\hline 220044408 & $22^{\mathrm{h}} 17^{\mathrm{m}} 34.47^{\mathrm{s}}$ & $+00^{\circ} 37^{\mathrm{m}} 33.52^{\mathrm{s}}$ & 2.9096 & 214 & 1 & 21.65 & 21.54 & 21.46 & 21.18 & point-like & FORS \\
\hline 220181962 & $22^{\mathrm{h}} 19^{\mathrm{m}} 36.35^{\mathrm{s}}$ & $+00^{\circ} 24^{\mathrm{m}} 34.58^{\mathrm{s}}$ & 2.8558 & 14 & 2 & 18.86 & 18.76 & 18.60 & 18.59 & extended & $\ldots$ \\
\hline 220208314 & $22^{\mathrm{h}} 20^{\mathrm{m}} 59.50^{\mathrm{s}}$ & $+00^{\circ} 38^{\mathrm{m}} 40.82^{\mathrm{s}}$ & 2.8204 & 14 & 2 & 23.33 & 22.64 & 21.74 & 21.57 & point-like & $\ldots$ \\
\hline 220514118 & $22^{\mathrm{h}} 17^{\mathrm{m}} 34.45^{\mathrm{s}}$ & $-00^{\circ} 03^{\mathrm{m}} 10.88^{\mathrm{s}}$ & 2.8136 & 14 & 2 & 23.65 & 23.05 & $\ldots$ & 22.19 & point-like & $\begin{array}{l}\cdots \\
\cdots\end{array}$ \\
\hline 220556037 & $22^{\mathrm{h}} 17^{\mathrm{m}} 05.53^{\mathrm{s}}$ & $+00^{\circ} 10^{\mathrm{m}} 19.85^{\mathrm{s}}$ & 2.7422 & 14 & 1 & 20.52 & 20.29 & 19.63 & 19.45 & point-like & $\ldots$ \\
\hline 220372036 & $22^{\mathrm{h}} 20^{\mathrm{m}} 02.78^{\mathrm{s}}$ & $-00^{\circ} 10^{\mathrm{m}} 09.28^{\mathrm{s}}$ & 2.7081 & 14 & 2 & $\ldots$ & $\ldots$ & $\ldots$ & 21.41 & point-like & $\ldots$ \\
\hline 220141562 & $22^{\mathrm{h}} 17^{\mathrm{m}} 34.71^{\mathrm{s}}$ & $+01^{\circ} 06^{\mathrm{m}} 26.48^{\mathrm{s}}$ & 2.6899 & 13 & 2 & ... $>>>>$ & $\ldots$ & & 22.12 & point-like & $\ldots$ \\
\hline 220001963 & $22^{\mathrm{h}} 13^{\mathrm{m}} 51.58^{\mathrm{s}}$ & $+00^{\circ} 25^{\mathrm{m}} 01.30^{\mathrm{s}}$ & 2.6801 & 14 & 1 & $\cdots$ & $\cdots$ & & 22.19 & point-like & $\ldots$ \\
\hline 220457748 & $22^{\mathrm{h}} 14^{\mathrm{m}} 09.13^{\mathrm{s}}$ & $-00^{\circ} 27^{\mathrm{m}} 17.14^{\mathrm{s}}$ & 2.6490 & 13 & 2 & $\cdots$ & $\cdots$ & $\cdots$ & 20.70 & point-like & $\ldots$ \\
\hline 220098629 & $22^{\mathrm{h}} 18^{\mathrm{m}} 01.51^{\mathrm{s}}$ & $+00^{\circ} 53^{\mathrm{m}} 19.83^{\mathrm{s}}$ & 2.5790 & 14 & 1 & & $\ldots$ & $\ldots$ & 21.71 & point-like & FORS \\
\hline 220404101 & $22^{\mathrm{h}} 21^{\mathrm{m}} 29.86^{\mathrm{s}}$ & $+00^{\circ} 04^{\mathrm{m}} 30.35^{\mathrm{s}}$ & 2.4827 & 14 & 2 & 19.27 & 19.09 & 19.08 & 19.19 & point-like & $\ldots$ \\
\hline 220446330 & $22^{\mathrm{h}} 20^{\mathrm{m}} 07.75^{\mathrm{s}}$ & $+00^{\circ} 23^{\mathrm{m}} 32.53^{\mathrm{s}}$ & 2.4149 & 13 & 2 & 21.67 & 21.03 & 20.68 & 20.39 & point-like & $\ldots$ \\
\hline 220544855 & $22^{\mathrm{h}} 17^{\mathrm{m}} 39.71^{\mathrm{s}}$ & $+00^{\circ} 06^{\mathrm{m}} 52.80^{\mathrm{s}}$ & 2.2934 & 14 & 1 & 21.97 & 21.61 & 21.00 & 20.91 & extended & FORS \\
\hline 220401794 & $22^{\mathrm{h}} 20^{\mathrm{m}} 57.43^{\mathrm{s}}$ & $+00^{\circ} 03^{\mathrm{m}} 30.33^{\mathrm{s}}$ & 2.2543 & 14 & 2 & 19.17 & 18.92 & 18.69 & 18.65 & point-like & $\ldots$ \\
\hline 220235977 & $22^{\mathrm{h}} 20^{\mathrm{m}} 52.76^{\mathrm{s}}$ & $+00^{\circ} 49^{\mathrm{m}} 18.10^{\mathrm{s}}$ & 2.1919 & 14 & 2 & 21.06 & 20.92 & 20.97 & 20.74 & point-like & \\
\hline 220567863 & $22^{\mathrm{h}} 16^{\mathrm{m}} 27.06^{\mathrm{s}}$ & $+00^{\circ} 14^{\mathrm{m}} 02.32^{\mathrm{s}}$ & 2.1610 & 14 & 1 & 21.00 & 20.02 & 21.10 & 20.79 & point-like & \\
\hline 220130245 & $22^{\mathrm{h}} 17^{\mathrm{m}} 52.14^{\mathrm{s}}$ & $+01^{\circ} 02^{\mathrm{m}} 59.22^{\mathrm{s}}$ & 2.1502 & 14 & 2 & & $\cdots$ & $\ldots$ & 19.65 & point-like & \\
\hline 220459956 & $22^{\mathrm{h}} 17^{\mathrm{m}} 11.07^{\mathrm{s}}$ & $-00^{\circ} 26^{\mathrm{m}} 19.47^{\mathrm{s}}$ & 2.1220 & 14 & 2 & & & & 21.03 & point-like & \\
\hline 220470488 & $22^{\mathrm{h}} 13^{\mathrm{m}} 55.40^{\mathrm{s}}$ & $-00^{\circ} 21^{\mathrm{m}} 40.75^{\mathrm{s}}$ & 2.0405 & 14 & 2 & $\cdots$ & $\ldots$ & $\cdots$ & 21.20 & point-like & $\cdots$ \\
\hline
\end{tabular}


Table B.1. continued.

\begin{tabular}{|c|c|c|c|c|c|c|c|c|c|c|c|}
\hline $\begin{array}{l}\text { Object ID } \\
\text { (1) }\end{array}$ & $\begin{array}{c}\alpha_{J 2000} \\
(2) \\
\end{array}$ & $\begin{array}{c}\delta_{J 2000} \\
(3) \\
\end{array}$ & $\begin{array}{c}z \\
(4) \\
\end{array}$ & $\begin{array}{r}\text { Flag } \\
(5) \\
\end{array}$ & $\begin{array}{l}\text { Epoch } \\
\text { (6) }\end{array}$ & $\begin{array}{l}B_{\mathrm{AB}} \\
(7)\end{array}$ & $\begin{array}{l}V_{\mathrm{AB}} \\
(8) \\
\end{array}$ & $\begin{array}{l}R_{\mathrm{AB}} \\
(9) \\
\end{array}$ & $\begin{array}{l}I_{\mathrm{AB}} \\
(10) \\
\end{array}$ & $\begin{array}{l}\text { Morphology } \\
\text { (11) }\end{array}$ & $\begin{array}{c}\text { Remark } \\
(12) \\
\end{array}$ \\
\hline 220463685 & $22^{\mathrm{h}} 17^{\mathrm{m}} 59.99^{\mathrm{s}}$ & $-00^{\circ} 24^{\mathrm{m}} 40.20^{\mathrm{s}}$ & 2.0300 & 14 & 2 & & & & 21.03 & point-like & \\
\hline 220125352 & $22^{\mathrm{h}} 14^{\mathrm{m}} 30.06^{\mathrm{s}}$ & $+01^{\circ} 01^{\mathrm{m}} 33.05^{\mathrm{s}}$ & 2.0128 & 14 & 2 & $\cdots$ & $\ldots$ & $\ldots$ & 21.19 & point-like & $\ldots$ \\
\hline 220531803 & $22^{\mathrm{h}} 13^{\mathrm{m}} 55.52^{\mathrm{s}}$ & $+00^{\circ} 02^{\mathrm{m}} 44.37^{\mathrm{s}}$ & 1.9932 & 14 & 2 & $\ldots$ & $\ldots$ & $\ldots$ & 21.75 & point-like & $\ldots$ \\
\hline 220562230 & $22^{\mathrm{h}} 17^{\mathrm{m}} 47.95^{\mathrm{s}}$ & $+00^{\circ} 12^{\mathrm{m}} 23.74^{\mathrm{s}}$ & 1.9711 & 13 & 2 & 21.95 & 21.81 & 21.94 & 21.32 & point-like & $\ldots$ \\
\hline 220365504 & $22^{\mathrm{h}} 20^{\mathrm{m}} 52.40^{\mathrm{s}}$ & $-00^{\circ} 13^{\mathrm{m}} 02.95^{\mathrm{s}}$ & 1.9447 & 13 & 2 & $\ldots$ & $\ldots$ & $\ldots$ & 21.69 & point-like & $\ldots$ \\
\hline 220551387 & $22^{\mathrm{h}} 16^{\mathrm{m}} 35.64^{\mathrm{s}}$ & $+00^{\circ} 09^{\mathrm{m}} 04.83^{\mathrm{s}}$ & 1.8810 & 13 & 2 & 21.23 & 21.69 & 21.04 & 21.42 & point-like & $\ldots$ \\
\hline 220082140 & $22^{\mathrm{h}} 15^{\mathrm{m}} 32.40^{\mathrm{s}}$ & $+00^{\circ} 48^{\mathrm{m}} 36.29^{\mathrm{s}}$ & 1.8484 & 14 & 1 & $\ldots$ & $\ldots$ & $\ldots$ & 20.59 & point-like & FORS \\
\hline 220090821 & $22^{\mathrm{h}} 15^{\mathrm{m}} 46.25^{\mathrm{s}}$ & $+00^{\circ} 50^{\mathrm{m}} 58.51^{\mathrm{s}}$ & 1.8326 & 13 & 1 & $\ldots$ & $\ldots$ & $\ldots$ & 20.40 & point-like & $\ldots$ \\
\hline 220308643 & $22^{\mathrm{h}} 20^{\mathrm{m}} 02.34^{\mathrm{s}}$ & $+01^{\circ} 13^{\mathrm{m}} 37.14^{\mathrm{s}}$ & 1.8007 & 13 & 2 & $\ldots$ & $\ldots$ & $\ldots$ & 21.75 & point-like & $\ldots$ \\
\hline 220438495 & $22^{\mathrm{h}} 20^{\mathrm{m}} 04.64^{\mathrm{s}}$ & $+00^{\circ} 20^{\mathrm{m}} 17.30^{\mathrm{s}}$ & 1.7738 & 13 & 2 & 23.02 & 22.54 & 22.25 & 21.82 & point-like & $\ldots$ \\
\hline 220370320 & $22^{\mathrm{h}} 18^{\mathrm{m}} 13.11^{\mathrm{s}}$ & $-00^{\circ} 11^{\mathrm{m}} 00.04^{\mathrm{s}}$ & 1.7445 & 13 & 2 & & 20.50 & & 20.06 & point-like & \\
\hline 220409734 & $22^{\mathrm{h}} 18^{\mathrm{m}} 16.60^{\mathrm{s}}$ & $+00^{\circ} 07^{\mathrm{m}} 01.37^{\mathrm{s}}$ & 1.7415 & 13 & 2 & 23.23 & 22.90 & 22.41 & 21.74 & point-like & $\ldots$ \\
\hline 220159199 & $22^{\mathrm{h}} 15^{\mathrm{m}} 57.05^{\mathrm{s}}$ & $+01^{\circ} 11^{\mathrm{m}} 40.39^{\mathrm{s}}$ & 1.7217 & 13 & 2 & $\ldots$ & $\ldots$ & $\ldots$ & 22.04 & point-like & $\ldots$ \\
\hline 220427244 & $22^{\mathrm{h}} 21^{\mathrm{m}} 28.67^{\mathrm{s}}$ & $+00^{\circ} 14^{\mathrm{m}} 44.01^{\mathrm{s}}$ & 1.6815 & 13 & 2 & 20.83 & 20.57 & 20.33 & 20.28 & point-like & $\ldots$ \\
\hline 220371301 & $22^{\mathrm{h}} 20^{\mathrm{m}} 28.72^{\mathrm{s}}$ & $-00^{\circ} 10^{\mathrm{m}} 28.43^{\mathrm{s}}$ & 1.6452 & 13 & 2 & $\ldots$ & $\ldots$ & $\ldots$ & 22.06 & point-like & \\
\hline 220566905 & $22^{\mathrm{h}} 14^{\mathrm{m}} 02.39^{\mathrm{s}}$ & $+00^{\circ} 13^{\mathrm{m}} 49.58^{\mathrm{s}}$ & 1.5285 & 13 & 1 & $\ldots$ & $\ldots$ & $\ldots$ & 22.27 & point-like & $\ldots$ \\
\hline 220610034 & $22^{\mathrm{h}} 18^{\mathrm{m}} 14.20^{\mathrm{s}}$ & $+00^{\circ} 20^{\mathrm{m}} 49.73^{\mathrm{s}}$ & 1.5135 & 14 & 1 & 20.77 & 20.86 & 20.60 & 20.54 & extended & FORS \\
\hline 220327763 & $22^{\mathrm{h}} 18^{\mathrm{m}} 29.94^{\mathrm{s}}$ & $-00^{\circ} 30^{\mathrm{m}} 35.89^{\mathrm{s}}$ & 1.5007 & 13 & 2 & $\ldots$ & $\ldots$ & $\ldots$ & 21.21 & point-like & $\ldots$ \\
\hline 220568559 & $22^{\mathrm{h}} 14^{\mathrm{m}} 43.23^{\mathrm{s}}$ & $+00^{\circ} 14^{\mathrm{m}} 16.29^{\mathrm{s}}$ & 1.4980 & 13 & 1 & & & & 22.10 & point-like & \\
\hline 220609820 & $22^{\mathrm{h}} 18^{\mathrm{m}} 29.04^{\mathrm{s}}$ & $+00^{\circ} 20^{\mathrm{m}} 24.32^{\mathrm{s}}$ & 1.4794 & 14 & 1 & 22.04 & 21.86 & 21.52 & 21.52 & extended & FORS \\
\hline 220419246 & $22^{\mathrm{h}} 20^{\mathrm{m}} 12.52^{\mathrm{s}}$ & $+00^{\circ} 10^{\mathrm{m}} 51.96^{\mathrm{s}}$ & 1.4786 & 13 & 2 & 21.54 & 21.54 & 20.80 & 20.62 & point-like & $\ldots$ \\
\hline 220041929 & $22^{\mathrm{h}} 15^{\mathrm{m}} 09.54^{\mathrm{s}}$ & $+00^{\circ} 36^{\mathrm{m}} 39.11^{\mathrm{s}}$ & 1.4751 & 13 & 1 & $\ldots$ & $\ldots$ & $\ldots$ & 18.23 & extended & $\ldots$ \\
\hline 220376198 & $22^{\mathrm{h}} 21^{\mathrm{m}} 30.08^{\mathrm{s}}$ & $-00^{\circ} 08^{\mathrm{m}} 18.91^{\mathrm{s}}$ & 1.4687 & 13 & 2 & $\ldots$ & $\ldots$ & $\ldots$ & 21.63 & point-like & $\ldots$ \\
\hline 220377744 & $22^{\mathrm{h}} 21^{\mathrm{m}} 44.12^{\mathrm{s}}$ & $-00^{\circ} 07^{\mathrm{m}} 39.17^{\mathrm{s}}$ & 1.4653 & 14 & 2 & & & $\ldots$ & 21.06 & point-like & $\ldots$ \\
\hline 220469918 & $22^{\mathrm{h}} 15^{\mathrm{m}} 31.85^{\mathrm{s}}$ & $-00^{\circ} 21^{\mathrm{m}} 54.28^{\mathrm{s}}$ & 1.4600 & 14 & 2 & . & $\ldots$ & $\ldots$ & 21.74 & extended & $\ldots$ \\
\hline 220326578 & $22^{\mathrm{h}} 20^{\mathrm{m}} 34.72^{\mathrm{s}}$ & $-00^{\circ} 31^{\mathrm{m}} 10.93^{\mathrm{s}}$ & 1.3913 & 14 & 2 & $\ldots$ & $\ldots$ & $\ldots$ & 22.07 & extended & $\ldots$ \\
\hline 220554600 & $22^{\mathrm{h}} 17^{\mathrm{m}} 36.64^{\mathrm{s}}$ & $+00^{\circ} 10^{\mathrm{m}} 05.86^{\mathrm{s}}$ & 1.3689 & 14 & 1 & 21.21 & 21.00 & 20.62 & 20.65 & point-like & FORS \\
\hline 220093875 & $22^{\mathrm{h}} 17^{\mathrm{m}} 48.64^{\mathrm{s}}$ & $+00^{\circ} 51^{\mathrm{m}} 50.39^{\mathrm{s}}$ & 1.3365 & 14 & 1 & $\ldots$ & & $\ldots$ & 21.83 & point-like & FORS \\
\hline 220542377 & $22^{\mathrm{h}} 17^{\mathrm{m}} 10.42^{\mathrm{s}}$ & $+00^{\circ} 06^{\mathrm{m}} 04.72^{\mathrm{s}}$ & 1.3097 & 13 & 1 & 22.24 & 21.95 & 21.53 & 21.12 & point-like & $\ldots$ \\
\hline 220054185 & $22^{\mathrm{h}} 15^{\mathrm{m}} 47.71^{\mathrm{s}}$ & $+00^{\circ} 40^{\mathrm{m}} 29.96^{\mathrm{s}}$ & 1.3057 & 14 & 1 & $\ldots$ & 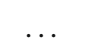 & $\ldots$ & 21.59 & point-like & $\ldots$ \\
\hline 220591287 & $22^{\mathrm{h}} 16^{\mathrm{m}} 49.05^{\mathrm{s}}$ & $+00^{\circ} 20^{\mathrm{m}} 46.27^{\mathrm{s}}$ & 1.2968 & 14 & 1 & 23.47 & 23.32 & 22.67 & 22.30 & extended & FORS \\
\hline 220525793 & $22^{\mathrm{h}} 14^{\mathrm{m}} 05.51^{\mathrm{s}}$ & $+00^{\circ} 00^{\mathrm{m}} 39.28^{\mathrm{s}}$ & 1.2940 & 13 & 2 & $\ldots$ & $\ldots$ & $\ldots$ & 19.01 & point-like & $\ldots$ \\
\hline 220154139 & $22^{\mathrm{h}} 14^{\mathrm{m}} 33.65^{\mathrm{s}}$ & $+01^{\circ} 10^{\mathrm{m}} 09.87^{\mathrm{s}}$ & 1.2903 & 13 & 2 & & & & 22.23 & extended & $\ldots$ \\
\hline 220247296 & $22^{\mathrm{h}} 21^{\mathrm{m}} 00.32^{\mathrm{s}}$ & $+00^{\circ} 53^{\mathrm{m}} 20.89^{\mathrm{s}}$ & 1.2846 & 13 & 2 & $\ldots$ & $\ldots$ & $\ldots$ & 21.41 & point-like & $\ldots$ \\
\hline 220613346 & $22^{\mathrm{h}} 18^{\mathrm{m}} 33.73^{\mathrm{s}}$ & $+00^{\circ} 27^{\mathrm{m}} 09.76^{\mathrm{s}}$ & 1.2530 & 14 & 1 & 21.63 & 21.25 & 20.41 & 20.39 & extended & FORS \\
\hline 220081925 & $22^{\mathrm{h}} 18^{\mathrm{m}} 00.42^{\mathrm{s}}$ & $+00^{\circ} 48^{\mathrm{m}} 31.41^{\mathrm{s}}$ & 1.2167 & 13 & 1 & 22.79 & 22.40 & 21.80 & 21.68 & extended & $\ldots$ \\
\hline 220375302 & $22^{\mathrm{h}} 21^{\mathrm{m}} 32.17^{\mathrm{s}}$ & $-00^{\circ} 08^{\mathrm{m}} 43.44^{\mathrm{s}}$ & 1.2082 & 13 & 2 & $\ldots$ & & $\ldots$ & 21.70 & extended & $\ldots$ \\
\hline 220255701 & $22^{\mathrm{h}} 19^{\mathrm{m}} 10.54^{\mathrm{s}}$ & $+00^{\circ} 56^{\mathrm{m}} 06.93^{\mathrm{s}}$ & 1.1932 & 14 & 2 & 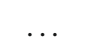 & & . & 19.64 & point-like & $\ldots$ \\
\hline 220567825 & $22^{\mathrm{h}} 15^{\mathrm{m}} 08.48^{\mathrm{s}}$ & $+00^{\circ} 14^{\mathrm{m}} 04.38^{\mathrm{s}}$ & 1.1601 & 13 & 1 & $\cdots$ & $\cdots$ & $\cdots$ & 21.07 & point-like & $\ldots$ \\
\hline 220561414 & $22^{\mathrm{h}} 17^{\mathrm{m}} 38.41^{\mathrm{s}}$ & $+00^{\circ} 12^{\mathrm{m}} 07.01^{\mathrm{s}}$ & 1.1243 & 14 & 2 & 20.60 & 20.24 & 20.09 & 19.98 & point-like & $\ldots$ \\
\hline 220357650 & $22^{\mathrm{h}} 19^{\mathrm{m}} 58.50^{\mathrm{s}}$ & $-00^{\circ} 16^{\mathrm{m}} 23.97^{\mathrm{s}}$ & 1.1228 & 13 & 2 & $\ldots$ & $\ldots$ & $\ldots$ & 22.21 & point-like & $\ldots$ \\
\hline 220458211 & $22^{\mathrm{h}} 17^{\mathrm{m}} 58.70^{\mathrm{s}}$ & $-00^{\circ} 27^{\mathrm{m}} 07.43^{\mathrm{s}}$ & 1.1049 & 13 & 2 & $\cdots$ & & $\cdots$ & 20.54 & point-like & $\ldots$ \\
\hline 220107230 & $22^{\mathrm{h}} 16^{\mathrm{m}} 56.10^{\mathrm{s}}$ & $+00^{\circ} 56^{\mathrm{m}} 00.77^{\mathrm{s}}$ & 1.0937 & 13 & 1 & $\cdots$ & $\cdots$ & $\ldots$ & 21.63 & point-like & $\ldots$ \\
\hline 220463317 & $22^{\mathrm{h}} 13^{\mathrm{m}} 56.02^{\mathrm{s}}$ & $-00^{\circ} 24^{\mathrm{m}} 55.47^{\mathrm{s}}$ & 1.0655 & 13 & 2 & $\ldots$ & $\ldots$ & $\ldots$ & 19.45 & point-like & $\ldots$ \\
\hline 220152300 & $22^{\mathrm{h}} 15^{\mathrm{m}} 04.35^{\mathrm{s}}$ & $+01^{\circ} 09^{\mathrm{m}} 35.55^{\mathrm{s}}$ & 1.0380 & 13 & 2 & $\ldots$ & $\ldots$ & $\ldots$ & 20.61 & point-like & $\ldots$ \\
\hline 220586430 & $22^{\mathrm{h}} 14^{\mathrm{m}} 34.82^{\mathrm{s}}$ & $+00^{\circ} 19^{\mathrm{m}} 24.18^{\mathrm{s}}$ & 1.0285 & 14 & 1 & $\cdots$ & & $\cdots$ & 20.35 & point-like & $\ldots$ \\
\hline 220125074 & $22^{\mathrm{h}} 17^{\mathrm{m}} 56.93^{\mathrm{s}}$ & $+01^{\circ} 01^{\mathrm{m}} 19.87^{\mathrm{s}}$ & 0.8640 & 14 & 2 & 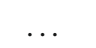 & & & 18.04 & extended & $\ldots$ \\
\hline 220149257 & $22^{\mathrm{h}} 17^{\mathrm{m}} 24.33^{\mathrm{s}}$ & $+01^{\circ} 08^{\mathrm{m}} 41.68^{\mathrm{s}}$ & 0.8477 & 14 & 2 & $\cdots$ & & $\cdots$ & 21.10 & point-like & $\ldots$ \\
\hline 220294100 & $22^{\mathrm{h}} 18^{\mathrm{m}} 15.60^{\mathrm{s}}$ & $+01^{\circ} 08^{\mathrm{m}} 42.69^{\mathrm{s}}$ & 0.7411 & 14 & 2 & & & $\ldots$ & 18.13 & point-like & $\ldots$ \\
\hline 220504239 & $22^{\mathrm{h}} 16^{\mathrm{m}} 23.77^{\mathrm{s}}$ & $-00^{\circ} 07^{\mathrm{m}} 28.36^{\mathrm{s}}$ & 0.7290 & 14 & 2 & $\ldots$ & $\ldots$ & $\ldots$ & 20.07 & point-like & $\ldots$ \\
\hline 220215958 & $22^{\mathrm{h}} 19^{\mathrm{m}} 51.28^{\mathrm{s}}$ & $+00^{\circ} 41^{\mathrm{m}} 35.99^{\mathrm{s}}$ & 0.6559 & 14 & 2 & 22.07 & 21.87 & 21.38 & 21.20 & point-like & $\ldots$ \\
\hline 220212912 & $22^{\mathrm{h}} 19^{\mathrm{m}} 07.95^{\mathrm{s}}$ & $+00^{\circ} 40^{\mathrm{m}} 23.90^{\mathrm{s}}$ & 0.6146 & 14 & 2 & 20.43 & 20.15 & 19.80 & 19.60 & extended & \\
\hline 220464758 & $22^{\mathrm{h}} 17^{\mathrm{m}} 50.50^{\mathrm{s}}$ & $-00^{\circ} 24^{\mathrm{m}} 25.59^{\mathrm{s}}$ & 0.5991 & 14 & 2 & $\ldots$ & $\ldots$ & $\ldots$ & 18.50 & extended & \\
\hline 220272017 & $22^{\mathrm{h}} 21^{\mathrm{m}} 33.76^{\mathrm{s}}$ & $+01^{\circ} 01^{\mathrm{m}} 19.75^{\mathrm{s}}$ & 0.5340 & 14 & 2 & & & . & 18.99 & extended & $\ldots$ \\
\hline 220608343 & $22^{\mathrm{h}} 18^{\mathrm{m}} 22.66^{\mathrm{s}}$ & $+00^{\circ} 17^{\mathrm{m}} 15.43^{\mathrm{s}}$ & 0.5240 & 14 & 2 & 21.01 & 20.92 & 20.51 & 20.25 & extended & $\ldots$ \\
\hline 220536609 & $22^{\mathrm{h}} 15^{\mathrm{m}} 31.65^{\mathrm{s}}$ & $+00^{\circ} 04^{\mathrm{m}} 18.31^{\mathrm{s}}$ & 0.4970 & 14 & 1 & & $\ldots$ & $\ldots$ & 21.09 & extended & \\
\hline 220554336 & $22^{\mathrm{h}} 14^{\mathrm{m}} 44.17^{\mathrm{s}}$ & $+00^{\circ} 10^{\mathrm{m}} 02.54^{\mathrm{s}}$ & 0.4470 & 14 & 1 & $\ldots$ & $\ldots$ & $\ldots$ & 21.02 & point-like & $\ldots$ \\
\hline
\end{tabular}


Table B.1. continued.

\begin{tabular}{cccccccccccc}
\hline \hline $\begin{array}{c}\text { Object ID } \\
(1)\end{array}$ & $\begin{array}{c}\alpha_{J 2000} \\
(2)\end{array}$ & $\begin{array}{c}\delta_{J 2000} \\
(3)\end{array}$ & $\begin{array}{c}z \\
(4)\end{array}$ & $\begin{array}{c}\text { Flag } \\
(5)\end{array}$ & $\begin{array}{c}\text { Epoch } \\
(6)\end{array}$ & $\begin{array}{c}B_{\mathrm{AB}} \\
(7)\end{array}$ & $\begin{array}{c}V_{\mathrm{AB}} \\
(8)\end{array}$ & $\begin{array}{c}R_{\mathrm{AB}} \\
(9)\end{array}$ & $\begin{array}{c}I_{\mathrm{AB}} \\
(10)\end{array}$ & $\begin{array}{c}\text { Morphology } \\
(11)\end{array}$ & $\begin{array}{c}\text { Remark } \\
(12)\end{array}$ \\
\hline 220355666 & $22^{\mathrm{h}} 18^{\mathrm{m}} 37.47^{\mathrm{s}}$ & $-00^{\circ} 17^{\mathrm{m}} 31.44^{\mathrm{s}}$ & 0.4394 & 14 & 2 & $\ldots$ & $\ldots$ & $\ldots$ & 18.01 & point-like & $\ldots$ \\
220209990 & $22^{\mathrm{h}} 19^{\mathrm{m}} 34.17^{\mathrm{s}}$ & $+00^{\circ} 39^{\mathrm{m}} 12.28^{\mathrm{s}}$ & 0.4062 & 14 & 2 & 20.60 & 20.50 & 19.69 & 19.65 & extended & $\ldots$ \\
220493749 & $22^{\mathrm{h}} 16^{\mathrm{m}} 08.78^{\mathrm{s}}$ & $-00^{\circ} 11^{\mathrm{m}} 42.07^{\mathrm{s}}$ & 0.3263 & 14 & 2 & $\ldots$ & $\ldots$ & $\ldots$ & 20.52 & point-like \\
220346642 & $22^{\mathrm{h}} 18^{\mathrm{m}} 52.40^{\mathrm{s}}$ & $-00^{\circ} 21^{\mathrm{m}} 33.62^{\mathrm{s}}$ & 0.3145 & 14 & 2 & $\ldots$ & $\ldots$ & $\ldots$ & 18.88 & extended \\
220257203 & $22^{\mathrm{h}} 18^{\mathrm{m}} 54.37^{\mathrm{s}}$ & $+00^{\circ} 56^{\mathrm{m}} 28.06^{\mathrm{s}}$ & 0.2513 & 14 & 2 & $\ldots$ & $\ldots$ & $\ldots$ & 18.23 & extended & $\ldots$ \\
\hline
\end{tabular}

Table columns: (1) Object identification number of the VVDS database; (2), (3) Right ascension and declination J2000.0; (4) Redshift; (5) Redshift quality flag. Flag 14 AGN have a 100\% secure redshift based on at least two emission lines. Flag 13 AGN have a redshift which is based on one broad emission line with a confident identification: either no other identification is verisimilar given our spectral wavelength coverage, or some faint additional features are supporting the chosen redshift; (6) VVDS observation epoch; (7), (8), (9), (10) $B, V, R, I$ magnitudes in the AB system. Photometry in the CDFS field is extracted from the EIS catalog (Arnouts et al. 2001) while in the 4 other fields it corresponds to the VVDS imaging survey (McCracken et al. 2003). These magnitudes are corrected for galactic extinction using the dust map provided by Schlegel et al. (1998); (11) Morphological classification in the $I$-band, based on the half-light radius of the object. Object with with $I_{\mathrm{AB}}>22.5$ or in the CDFS and VVDS-1400+05 field are not classified (See Gavignaud et al. 2006, Sect. 7); (12) We indicate here, AGN for which a single broad emission line is detected in the VVDS original spectrum but for which a second line is detected at shorter wavelength either in our VIMOS and FORS follow-up programs, or in one of these spectroscopic survey: 2Qz (Croom et al. 2004), SDSS DR6 (Adelman-McCarthy \& the SDSS Collaboration 2007), and the spectroscopic catalog of the CDFS (Szokoly et al. 2004).

Table B.2. AGN with a single emission line detected (flag 19).

\begin{tabular}{|c|c|c|c|c|c|c|c|c|c|c|}
\hline $\begin{array}{c}\text { Object ID } \\
\text { (1) }\end{array}$ & $\begin{array}{c}\alpha_{J 2000} \\
(2)\end{array}$ & $\begin{array}{c}\delta_{J 2000} \\
(3)\end{array}$ & $\begin{array}{c}\text { Epoch } \\
\text { (4) }\end{array}$ & $\begin{array}{l}\lambda_{\mathrm{BL}} \\
(5)\end{array}$ & $\begin{array}{l}z \text { solutions } \\
\text { (6) }\end{array}$ & $\begin{array}{l}B_{\mathrm{AB}} \\
\text { (7) }\end{array}$ & $\begin{array}{l}V_{\mathrm{AB}} \\
(8)\end{array}$ & $\begin{array}{l}R_{\mathrm{AB}} \\
(9)\end{array}$ & $\begin{array}{l}I_{\mathrm{AB}} \\
(10)\end{array}$ & $\begin{array}{l}\text { Morphology } \\
\text { (11) }\end{array}$ \\
\hline CDFS: & deep mode & 2 AGN & & & & & & & & \\
\hline 000031270 & $03^{\mathrm{h}} 32^{\mathrm{m}} 57.74^{\mathrm{s}}$ & $-27^{\circ} 43^{\mathrm{m}} 50.12^{\mathrm{s}}$ & 1 & 7319. & $0.1150^{a} 1.6150^{b}$ & 23.81 & 23.65 & 23.44 & 23.52 & \\
\hline 000017025 & $03^{\mathrm{h}} 31^{\mathrm{m}} 54.30^{\mathrm{s}}$ & $-27^{\circ} 53^{\mathrm{m}} 49.58^{\mathrm{s}}$ & 1 & 6500. & $1.3220^{b} 2.4050^{c} 3.1960^{d}$ & 24.78 & 24.51 & 23.93 & 23.70 & $\ldots$ \\
\hline 0226-04: & deep mode & $6 \mathrm{AGN}$ & & & & & & & & \\
\hline 020375508 & $02^{\mathrm{h}} 25^{\mathrm{m}} 48.99^{\mathrm{s}}$ & $-04^{\circ} 10^{\mathrm{m}} 28.04^{\mathrm{s}}$ & 1 & 5963. & $1.1300^{b} 2.1240^{c} 2.8500^{d}$ & 23.25 & 22.98 & 23.05 & 22.54 & \\
\hline 020293248 & $02^{\mathrm{h}} 26^{\mathrm{m}} 25.92^{\mathrm{s}}$ & $-04^{\circ} 21^{\mathrm{m}} 12.73^{\mathrm{s}}$ & 1 & 7335. & $0.1180^{a} 1.6210^{b}$ & 24.79 & 24.54 & 24.14 & 23.26 & $\ldots$ \\
\hline 020281035 & $02^{\mathrm{h}} 26^{\mathrm{m}} 12.30^{\mathrm{s}}$ & $-04^{\circ} 22^{\mathrm{m}} 51.63^{\mathrm{s}}$ & 1 & 6805. & $0.0370^{a} 1.4310^{b} 2.5650^{c} 3.3930^{d}$ & 25.07 & 24.39 & 24.07 & 23.93 & \\
\hline 020469530 & $02^{\mathrm{h}} 26^{\mathrm{m}} 49.92^{\mathrm{s}}$ & $-04^{\circ} 15^{\mathrm{m}} 17.44^{\mathrm{s}}$ & 1 & 6701. & $0.0210^{a} 1.3940^{b} 2.5100^{c} 3.3260^{d}$ & 24.69 & 24.36 & 24.28 & 23.50 & $\ldots$ \\
\hline 020225567 & $02^{\mathrm{h}} 27^{\mathrm{m}} 06.42^{\mathrm{s}}$ & $-04^{\circ} 30^{\mathrm{m}} 14.34^{\mathrm{s}}$ & 1 & 6558. & $1.3430^{b} 2.4350^{c}$ & 24.65 & 24.26 & 23.74 & 23.07 & $\cdots$ \\
\hline 020137737 & $02^{\mathrm{h}} 26^{\mathrm{m}} 47.76^{\mathrm{s}}$ & $-04^{\circ} 42^{\mathrm{m}} 04.06^{\mathrm{s}}$ & 1 & 6320. & $1.2580^{b} 2.3110^{c} 3.0800^{d}$ & 24.59 & 24.15 & 24.17 & 23.78 & $\ldots$ \\
\hline 1003+01: & Wide mode & $5 \mathrm{AGN}$ & & & & & & & & \\
\hline 100093239 & $10^{\mathrm{h}} 07^{\mathrm{m}} 38.99^{\mathrm{s}}$ & $+01^{\circ} 16^{\mathrm{m}} 38.69^{\mathrm{s}}$ & 2 & 7554. & $0.1510^{a} 1.7000^{b}$ & & & & 20.29 & point-like \\
\hline 100461830 & $10^{\mathrm{h}} 03^{\mathrm{m}} 48.70^{\mathrm{s}}$ & $+02^{\circ} 10^{\mathrm{m}} 45.16^{\mathrm{s}}$ & 2 & 6700. & $0.0210^{a} 1.3950^{b} 2.5100^{c} 3.3250^{d}$ & 21.86 & 21.78 & 21.70 & 21.37 & extended \\
\hline 100361479 & $10^{\mathrm{h}} 03^{\mathrm{m}} 43.19^{\mathrm{s}}$ & $+01^{\circ} 57^{\mathrm{m}} 03.28^{\mathrm{s}}$ & 2 & 6564. & $1.3460^{b} 2.4380^{c}$ & 23.11 & 22.75 & 22.49 & 22.10 & extended \\
\hline 100393370 & $10^{\mathrm{h}} 03^{\mathrm{m}} 36.11^{\mathrm{s}}$ & $+02^{\circ} 01^{\mathrm{m}} 30.20^{\mathrm{s}}$ & 2 & 6383. & $1.2810^{b} 2.3440^{c}$ & 22.49 & 22.34 & 22.68 & 22.16 & point-like \\
\hline 100573419 & $10^{\mathrm{h}} 04^{\mathrm{m}} 14.34^{\mathrm{s}}$ & $+02^{\circ} 27^{\mathrm{m}} 17.66^{\mathrm{s}}$ & 2 & 6381. & $1.2810^{b} 2.3430^{c}$ & 22.86 & 22.21 & 22.13 & 21.78 & extended \\
\hline 1400+05: & Wide mode & 12 AGN & & & & & & & & \\
\hline 140421262 & $13^{\mathrm{h}} 58^{\mathrm{m}} 39.67^{\mathrm{s}}$ & $+05^{\circ} 09^{\mathrm{m}} 40.06^{\mathrm{s}}$ & 2 & 6155. & $1.2000^{b} 2.2240^{c} 2.9740^{d}$ & 19.92 & 19.72 & 19.60 & 19.85 & \\
\hline 140242524 & $13^{\mathrm{h}} 55^{\mathrm{m}} 50.62^{\mathrm{s}}$ & $+04^{\circ} 42^{\mathrm{m}} 21.20^{\mathrm{s}}$ & 2 & 6804. & $0.0370^{a} 1.4320^{b} 2.5640^{c}$ & $\ldots$ & $\ldots$ & $\ldots$ & 21.59 & $\cdots$ \\
\hline 140304399 & $14^{\mathrm{h}} 01^{\mathrm{m}} 25.45^{\mathrm{s}}$ & $+04^{\circ} 51^{\mathrm{m}} 27.48^{\mathrm{s}}$ & 2 & 6256. & $1.2360^{b} 2.2770^{c}$ & 22.84 & 22.44 & 22.20 & 21.91 & $\ldots$ \\
\hline 140361276 & $13^{\mathrm{h}} 59^{\mathrm{m}} 29.99^{\mathrm{s}}$ & $+04^{\circ} 59^{\mathrm{m}} 32.38^{\mathrm{s}}$ & 2 & 5775. & $1.0640^{b} 2.0250^{c}$ & 21.89 & 21.51 & 21.73 & 21.55 & $\ldots$ \\
\hline 140242100 & $14^{\mathrm{h}} 00^{\mathrm{m}} 33.03^{\mathrm{s}}$ & $+04^{\circ} 42^{\mathrm{m}} 22.67^{\mathrm{s}}$ & 2 & 7720. & $0.1760^{a} 1.7590^{b}$ & 23.08 & 22.78 & 22.42 & 21.94 & $\ldots$ \\
\hline 140364738 & $13^{\mathrm{h}} 58^{\mathrm{m}} 17.25^{\mathrm{s}}$ & $+04^{\circ} 59^{\mathrm{m}} 56.90^{\mathrm{s}}$ & 2 & 6773. & $0.0320^{a} 1.4210^{b} 2.5480^{c}$ & 20.66 & 20.27 & 20.00 & 20.48 & $\ldots$ \\
\hline 140450459 & $13^{\mathrm{h}} 58^{\mathrm{m}} 33.08^{\mathrm{s}}$ & $+05^{\circ} 14^{\mathrm{m}} 40.05^{\mathrm{s}}$ & 2 & 6657. & $0.0140^{a} 1.3790^{b} 2.4870^{c}$ & 21.64 & 21.58 & 21.35 & 21.55 & $\ldots$ \\
\hline 140387670 & $13^{\mathrm{h}} 59^{\mathrm{m}} 22.13^{\mathrm{s}}$ & $+05^{\circ} 03^{\mathrm{m}} 53.84^{\mathrm{s}}$ & 2 & 6590. & $0.0040^{a} 1.3550^{b} 2.4520^{c}$ & 21.71 & 21.36 & 21.11 & 21.12 & $\ldots$ \\
\hline 140268727 & $13^{\mathrm{h}} 59^{\mathrm{m}} 46.93^{\mathrm{s}}$ & $+04^{\circ} 46^{\mathrm{m}} 14.84^{\mathrm{s}}$ & 2 & 6584. & $0.0030^{a} 1.3530^{b} 2.4490^{c}$ & $\ldots$ & $\ldots$ & 19.13 & 19.22 & $\ldots$ \\
\hline 140276121 & $14^{\mathrm{h}} 00^{\mathrm{m}} 26.72^{\mathrm{s}}$ & $+04^{\circ} 47^{\mathrm{m}} 19.30^{\mathrm{s}}$ & 2 & 6564. & $1.3460^{b} 2.4390^{c}$ & 19.87 & 19.69 & 19.90 & 19.85 & $\ldots$ \\
\hline 140373173 & $13^{\mathrm{h}} 58^{\mathrm{m}} 37.46^{\mathrm{s}}$ & $+05^{\circ} 01^{\mathrm{m}} 22.89^{\mathrm{s}}$ & 2 & 6090. & $1.1770^{b} 2.1900^{c} 2.9320^{d}$ & 22.56 & 21.75 & 21.56 & 21.76 & $\ldots$ \\
\hline 140312115 & $13^{\mathrm{h}} 57^{\mathrm{m}} 41.81^{\mathrm{s}}$ & $+04^{\circ} 52^{\mathrm{m}} 33.24^{\mathrm{s}}$ & 2 & 6041. & $1.1590^{b} 2.1640^{c}$ & $\ldots$ & $\ldots$ & 21.72 & 22.16 & $\ldots$ \\
\hline $2217+00:$ & Wide mode & 38 AGN & & & & & & & & \\
\hline 220525641 & $22^{\mathrm{h}} 16^{\mathrm{m}} 31.69^{\mathrm{s}}$ & $+00^{\circ} 00^{\mathrm{m}} 38.07^{\mathrm{s}}$ & 2 & 6874. & $0.0470^{a} 1.4570^{b} 2.6010^{c}$ & 21.77 & 21.69 & 21.41 & 21.44 & point-like \\
\hline 220266865 & $22^{\mathrm{h}} 20^{\mathrm{m}} 50.58^{\mathrm{s}}$ & $+00^{\circ} 59^{\mathrm{m}} 48.73^{\mathrm{s}}$ & 2 & 6840. & $0.0420^{a} 1.4450^{b} 2.5830^{c} 3.4160^{d}$ & $\ldots$ & $\cdots$ & $\cdots$ & 19.73 & point-like \\
\hline 220277254 & $22^{\mathrm{h}} 20^{\mathrm{m}} 54.48^{\mathrm{s}}$ & $+01^{\circ} 03^{\mathrm{m}} 10.78^{\mathrm{s}}$ & 2 & 6450. & $1.3050^{b} 2.3780^{c}$ & $\cdots$ & $\cdots$ & & 20.91 & point-like \\
\hline 220145240 & $22^{\mathrm{h}} 14^{\mathrm{m}} 06.83^{\mathrm{s}}$ & $+01^{\circ} 07^{\mathrm{m}} 29.30^{\mathrm{s}}$ & 2 & 6364. & $1.2750^{b} 2.3340^{c}$ & & & & 22.24 & point-like \\
\hline
\end{tabular}


Table B.2. continued.

\begin{tabular}{|c|c|c|c|c|c|c|c|c|c|c|}
\hline $\begin{array}{l}\text { Object ID } \\
\text { (1) }\end{array}$ & $\begin{array}{c}\alpha_{J 2000} \\
(2)\end{array}$ & $\begin{array}{c}\delta_{J 2000} \\
(3)\end{array}$ & $\begin{array}{l}\text { Epoch } \\
\text { (4) }\end{array}$ & $\begin{array}{l}\lambda_{\mathrm{BL}} \\
(5)\end{array}$ & $\begin{array}{c}z \text { solutions } \\
\text { (6) }\end{array}$ & $\begin{array}{l}B_{\mathrm{AB}} \\
(7)\end{array}$ & $\begin{array}{l}V_{\mathrm{AB}} \\
(8)\end{array}$ & $\begin{array}{l}R_{\mathrm{AB}} \\
(9)\end{array}$ & $\begin{array}{l}I_{\mathrm{AB}} \\
(10)\end{array}$ & $\begin{array}{l}\text { Morphology } \\
\text { (11) }\end{array}$ \\
\hline 220430837 & $22^{\mathrm{h}} 19^{\mathrm{m}} 58.43^{\mathrm{s}}$ & $+00^{\circ} 16^{\mathrm{m}} 30.20^{\mathrm{s}}$ & 2 & 6193. & $1.2130^{b} 2.2440^{c}$ & 21.35 & 21.14 & 21.06 & 20.72 & extended \\
\hline 220056092 & $22^{\mathrm{h}} 13^{\mathrm{m}} 53.81^{\mathrm{s}}$ & $+00^{\circ} 41^{\mathrm{m}} 06.90^{\mathrm{s}}$ & 1 & 6100. & $1.1790^{b} 2.1950^{c}$ & $\ldots$ & $\ldots$ & $\ldots$ & 22.09 & point-like \\
\hline 220514141 & $22^{\mathrm{h}} 15^{\mathrm{m}} 28.78^{\mathrm{s}}$ & $-00^{\circ} 03^{\mathrm{m}} 01.29^{\mathrm{s}}$ & 2 & 5956. & $1.1290^{b} 2.1200^{c}$ & $\ldots$ & $\ldots$ & . & 22.16 & extended \\
\hline 220456500 & $22^{\mathrm{h}} 17^{\mathrm{m}} 24.92^{\mathrm{s}}$ & $-00^{\circ} 27^{\mathrm{m}} 49.19^{\mathrm{s}}$ & 2 & 8524. & $0.2990^{a} 2.0460^{b}$ & & & & 22.35 & point-like \\
\hline 220551735 & $22^{\mathrm{h}} 18^{\mathrm{m}} 05.78^{\mathrm{s}}$ & $+00^{\circ} 09^{\mathrm{m}} 12.66^{\mathrm{s}}$ & 1 & 8056. & $0.2270^{a} 1.8780^{b}$ & 21.73 & 21.72 & 21.14 & 21.12 & point-like \\
\hline 220450780 & $22^{\mathrm{h}} 16^{\mathrm{m}} 37.41^{\mathrm{s}}$ & $-00^{\circ} 30^{\mathrm{m}} 27.37^{\mathrm{s}}$ & 2 & 7543. & $0.1490^{a} 1.6960^{b}$ & $\ldots$ & $\ldots$ & $\ldots$ & 21.31 & extended \\
\hline 220514417 & $22^{\mathrm{h}} 15^{\mathrm{m}} 30.67^{\mathrm{s}}$ & $-00^{\circ} 02^{\mathrm{m}} 57.02^{\mathrm{s}}$ & 2 & 7387. & $0.1260^{a} 1.6400^{b}$ & $\cdots$ & $\cdots$ & & 21.20 & point-like \\
\hline 220583713 & $22^{\mathrm{h}} 15^{\mathrm{m}} 34.70^{\mathrm{s}}$ & $+00^{\circ} 18^{\mathrm{m}} 42.01^{\mathrm{s}}$ & 1 & 7352. & $0.1200^{a} 1.6270^{b}$ & & & & 21.89 & point-like \\
\hline 220153188 & $22^{\mathrm{h}} 15^{\mathrm{m}} 42.00^{\mathrm{s}}$ & $+01^{\circ} 09^{\mathrm{m}} 54.38^{\mathrm{s}}$ & 2 & 7280. & $0.1090^{a} 1.6020^{b}$ & & & & 22.00 & int-like \\
\hline 220415034 & $22^{\mathrm{h}} 21^{\mathrm{m}} 01.42^{\mathrm{s}}$ & $+00^{\circ} 09^{\mathrm{m}} 11.33^{\mathrm{s}}$ & 2 & 7206. & $0.0980^{a} 1.5750^{b}$ & 21.73 & 21.68 & 21.40 & 21.08 & point-like \\
\hline 220417000 & $22^{\mathrm{h}} 21^{\mathrm{m}} 16.89^{\mathrm{s}}$ & $+00^{\circ} 10^{\mathrm{m}} 01.43^{\mathrm{s}}$ & 2 & 7181. & $0.0940^{a} 1.5660^{b}$ & 22.87 & 22.40 & 21.88 & 21.40 & int-like \\
\hline 220442138 & $22^{\mathrm{h}} 21^{\mathrm{m}} 02.71^{\mathrm{s}}$ & $+00^{\circ} 22^{\mathrm{m}} 06.71^{\mathrm{s}}$ & 2 & 7037. & $0.0720^{a} 1.5150^{b}$ & 22.15 & 22.21 & 21.64 & 21.47 & t-like \\
\hline 220023681 & $22^{\mathrm{h}} 17^{\mathrm{m}} 46.44^{\mathrm{s}}$ & $+00^{\circ} 31^{\mathrm{m}} 26.58^{\mathrm{s}}$ & 1 & 6956. & $0.0600^{a} 1.4850^{b} 2.6440^{c}$ & 24.33 & 23.25 & 22.14 & 21.71 & -like \\
\hline 220593613 & $22^{\mathrm{h}} 14^{\mathrm{m}} 11.61^{\mathrm{s}}$ & $+00^{\circ} 21^{\mathrm{m}} 29.15^{\mathrm{s}}$ & 1 & 6893. & $0.0500^{a} 1.4630^{b} 2.6110^{c}$ & 2ד. & & & 21.89 & ded \\
\hline 220248236 & $22^{\mathrm{h}} 20^{\mathrm{m}} 35.99^{\mathrm{s}}$ & $+00^{\circ} 53^{\mathrm{m}} 39.78^{\mathrm{s}}$ & 2 & 6787. & $0.0340^{a} 1.4260^{b} 2.5$ & & $\ldots$ & & 21.75 & -like \\
\hline 220548678 & $22^{\mathrm{h}} 15^{\mathrm{m}} 02.71^{\mathrm{s}}$ & $+00^{\circ} 08^{\mathrm{m}} 10.56^{\mathrm{s}}$ & 1 & 6766. & $0.0310^{a} 1.4170^{b} 2.54$ & & & & 21.98 & it-like \\
\hline 220450644 & $22^{\mathrm{h}} 14^{\mathrm{m}} 59.31^{\mathrm{s}}$ & $-00^{\circ} 30^{\mathrm{m}} 32.88^{\mathrm{s}}$ & 2 & 6682. & $0.0180^{a} 1.3880^{b} 2.5000^{c}$ & & & & 19.81 & point-like \\
\hline 220367657 & $22^{\mathrm{h}} 19^{\mathrm{m}} 11.81^{\mathrm{s}}$ & $-00^{\circ} 12^{\mathrm{m}} 07.27^{\mathrm{s}}$ & 2 & 6642. & $0.0120^{a} 1.3740^{b} 2.4790^{c}$ & & 20.89 & & 20.44 & extended \\
\hline 220340940 & $22^{\mathrm{h}} 19^{\mathrm{m}} 55.93^{\mathrm{s}}$ & $-00^{\circ} 24^{\mathrm{m}} 12.15^{\mathrm{s}}$ & 2 & 6627. & $0.0100^{a} 1.3690^{b} 2.4720^{c}$ & & & & 21.19 & point-like \\
\hline 220528506 & $22^{\mathrm{h}} 17^{\mathrm{m}} 14.92^{\mathrm{s}}$ & $+00^{\circ} 01^{\mathrm{m}} 34.79^{\mathrm{s}}$ & 2 & 6625. & $0.0090^{a} 1.3680^{b} 2.4700^{c}$ & 21.70 & 21.70 & 21.70 & 21.42 & extended \\
\hline 220293272 & $22^{\mathrm{h}} 19^{\mathrm{m}} 51.69^{\mathrm{s}}$ & $+01^{\circ} 08^{\mathrm{m}} 34.19^{\mathrm{s}}$ & 2 & 6600. & $0.0060^{a} 1.3590^{b} 2.4570^{c}$ & & & & 20.20 & point-like \\
\hline 220416619 & $22^{\mathrm{h}} 21^{\mathrm{m}} 00.87^{\mathrm{s}}$ & $+00^{\circ} 09^{\mathrm{m}} 51.78^{\mathrm{s}}$ & 2 & 6586. & $0.0040^{a} 1.3540^{b} 2.4500^{c}$ & 21.87 & 21.70 & 21.63 & 21.41 & point-like \\
\hline 220450790 & $22^{\mathrm{h}} 16^{\mathrm{m}} 36.78^{\mathrm{s}}$ & $-00^{\circ} 30^{\mathrm{m}} 25.92^{\mathrm{s}}$ & 2 & 6574. & $0.0020^{a} 1.3490^{b} 2.4440^{c}$ & & & & 21.84 & point-like \\
\hline 220417927 & $22^{\mathrm{h}} 20^{\mathrm{m}} 52.10^{\mathrm{s}}$ & $+00^{\circ} 10^{\mathrm{m}} 25.42^{\mathrm{s}}$ & 2 & 6574. & $0.0020^{a} 1.3490^{b} 2.4430^{c}$ & 22.26 & 22.05 & 21.70 & 21.23 & point-like \\
\hline 220527985 & $22^{\mathrm{h}} 17^{\mathrm{m}} 48.67^{\mathrm{s}}$ & $+00^{\circ} 01^{\mathrm{m}} 25.97^{\mathrm{s}}$ & 2 & 6546. & $1.3390^{b} 2.4290^{c}$ & 21.97 & 22.02 & 21.50 & 21.82 & point-like \\
\hline 220260114 & $22^{\mathrm{h}} 18^{\mathrm{m}} 52.63^{\mathrm{s}}$ & $+00^{\circ} 57^{\mathrm{m}} 40.38^{\mathrm{s}}$ & 2 & 6467. & $1.3110^{b} 2.3880^{c}$ & & & & 21.98 & point-like \\
\hline 220234909 & $22^{\mathrm{h}} 18^{\mathrm{m}} 13.40^{\mathrm{s}}$ & $+00^{\circ} 48^{\mathrm{m}} 54.05^{\mathrm{s}}$ & 1 & 6407. & $1.2890^{b} 2.3560^{c} 3.1360^{d}$ & 23.40 & 22.55 & 21.99 & 21.88 & extended \\
\hline 220457558 & $22^{\mathrm{h}} 15^{\mathrm{m}} 42.94^{\mathrm{s}}$ & $-00^{\circ} 27^{\mathrm{m}} 21.12^{\mathrm{s}}$ & 2 & 6378. & $1.2790^{b} 2.3410^{c}$ & & & & 22.10 & point-like \\
\hline 220216575 & $22^{\mathrm{h}} 20^{\mathrm{m}} 02.85^{\mathrm{s}}$ & $+00^{\circ} 41^{\mathrm{m}} 50.22^{\mathrm{s}}$ & 2 & 6361. & $1.2730^{b} 2.3320^{c} 3.1070^{d}$ & 21.43 & 21.43 & 21.20 & 21.31 & -like \\
\hline 220515291 & $22^{\mathrm{h}} 18^{\mathrm{m}} 02.63^{\mathrm{s}}$ & $-00^{\circ} 02^{\mathrm{m}} 39.74^{\mathrm{s}}$ & 2 & 6319. & $1.2580^{b} 2.3100^{c}$ & 23.15 & 23.14 & 22.57 & 21.87 & aded \\
\hline 069 & $22^{\mathrm{h}} 21^{\mathrm{m}} 03.65^{\mathrm{s}}$ & $+00^{\circ} 22^{\mathrm{m}} 04.02^{\mathrm{s}}$ & 2 & 6119. & $1.1870^{b} 2.2050^{c}$ & 21.39 & 21.25 & 21.28 & 21.03 & -like \\
\hline 399800 & $22^{\mathrm{h}} 20^{\mathrm{m}} 14.86^{\mathrm{s}}$ & $+00^{\circ} 02^{\mathrm{m}} 46.33^{\mathrm{s}}$ & 2 & 6092. & $1.1770^{b} 2.1910^{c}$ & 22.76 & 22.30 & 22.03 & 21.96 & \\
\hline 220608923 & $22^{\mathrm{h}} 18^{\mathrm{m}} 33.29^{\mathrm{s}}$ & $+00^{\circ} 18^{\mathrm{m}} 35.17^{\mathrm{s}}$ & 2 & 6007. & $1.1470^{b} 2.1470^{c}$ & 22.01 & 21.58 & 21.14 & 21.58 & ike \\
\hline 220371718 & $22^{\mathrm{h}} 18^{\mathrm{m}} 15.48^{\mathrm{s}}$ & $-00^{\circ} 10^{\mathrm{m}} 19.03^{\mathrm{s}}$ & 2 & 5984. & $1.1390^{b} 2.1350^{c}$ & 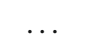 & 21.95 & $\ldots$ & 21.67 & point-like \\
\hline
\end{tabular}

Table columns: (1) Object identification number of the VVDS database; (2), (3) Right ascension and declination J2000.0; (4) VVDS observation epoch; (5), (6) Observed wavelength of the broad-emission line and possible redshifts. Superscript indicate the identifications for the emission line: $a, b, c, d$ respectively correspond to $\mathrm{H} \alpha$., $\mathrm{Mg}$ II, C III, and C IV; (7), (8), (9), (10) $B, V, R, I$ magnitudes in the AB system (see Table B.1); (11) Morphological classification in the $I$-band (see Table B.1).

\section{References}

Adelman-McCarthy, J. K., \& the SDSS Collaboration. 2007, ArXiv e-prints, 707 Arnouts, S., Vandame, B., Benoist, C., et al. 2001, A\&A, 379, 740

Babić, A., Miller, L., Jarvis, M. J., et al. 2007, A\&A, 474, 755

Baskin, A., \& Laor, A. 2005, MNRAS, 356, 1029

Bentz, M. C., Peterson, B. M., Pogge, R. W., Vestergaard, M., \& Onken, C. A. 2006, ApJ, 644, 133

Bongiorno, A., Zamorani, G., Gavignaud, I., et al. 2007, A\&A, 472, 443

Cattaneo, A. 2001, MNRAS, 324, 128

Collin, S., Kawaguchi, T., Peterson, B. M., \& Vestergaard, M. 2006, A\&A, 456, 75

Croom, S. M., Smith, R. J., Boyle, B. J., et al. 2004, MNRAS, 349, 1397 Ferrarese, L., \& Merritt, D. 2000, ApJ, 539, L9

Fine, S., Croom, S. M., Hopkins, P. F., et al. 2008, ArXiv e-prints, 807

Garilli, B., Le Fèvre, O., Guzzo, L., et al. 2008, ArXiv e-prints, 804 Gaskell, C. M. 1982, ApJ, 263, 79

Gavignaud, I., Bongiorno, A., Paltani, S., et al. 2006, A\&A, 457, 79

Gebhardt, K., Bender, R., Bower, G., et al. 2000, ApJ, 539, L13

Hasinger, G., Miyaji, T., \& Schmidt, M. 2005, A\&A, 441, 417

Hopkins, P. F., Hernquist, L., Cox, T. J., et al. 2006, ApJ, 639, 700

Hopkins, P. F., Richards, G. T., \& Hernquist, L. 2007, ApJ, 654, 731

Kaspi, S., Brandt, W. N., Maoz, D., et al. 2007, ApJ, 659, 997

Kollmeier, J. A., Onken, C. A., Kochanek, C. S., et al. 2006, ApJ, 648, 128

Le Fèvre, O., Vettolani, G., Garilli, B., et al. 2005, A\&A, 439, 845
Marconi, A., Risaliti, G., Gilli, R., et al. 2004, MNRAS, 351, 169

Marconi, A., Axon, D. J., Maiolino, R., et al. 2008, ApJ, 678, 693

McCracken, H. J., Radovich, M., Bertin, E., et al. 2003, A\&A, 410, 17

McLure, R. J., \& Dunlop, J. S. 2004, MNRAS, 352, 1390

McLure, R. J., \& Jarvis, M. J. 2002, MNRAS, 337, 109

Netzer, H., Lira, P., Trakhtenbrot, B., Shemmer, O., \& Cury, I. 2007, ApJ, 671, 1256

Paltani, S., \& Türler, M. 2005, A\&A, 435, 811

Richards, G. T., Fan, X., Newberg, H. J., et al. 2002, AJ, 123, 2945

Richards, G. T., Strauss, M. A., Fan, X., et al. 2006, AJ, 131, 2766

Schlegel, D. J., Finkbeiner, D. P., \& Davis, M. 1998, ApJ, 500, 525

Shen, Y., Greene, J. E., Strauss, M. A., Richards, G. T., \& Schneider, D. P. 2008, ApJ, 680, 169

Sigut, T. A. A., \& Pradhan, A. K. 2003, ApJS, 145, 15

Soltan, A. 1982, MNRAS, 200, 115

Steffen, A. T., Strateva, I., Brandt, W. N., et al. 2006, AJ, 131, 2826

Szokoly, G. P., Bergeron, J., Hasinger, G., et al. 2004, ApJS, 155, 271

Tytler, D., \& Fan, X.-M. 1992, ApJS, 79, 1

Vestergaard, M. 2002, ApJ, 571, 733

Vestergaard, M., \& Peterson, B. M. 2006, ApJ, 641, 689

Vestergaard, M., \& Wilkes, B. J. 2001, ApJS, 134, 1

Wolf, C., Wisotzki, L., Borch, A., et al. 2003, A\&A, 408, 499

Woo, J.-H., \& Urry, C. M. 2002, ApJ, 579, 530

Yu, Q., \& Tremaine, S. 2002, MNRAS, 335, 965 